Review

\title{
Lipids around the Clock: Focus on Circadian Rhythms and Lipid Metabolism
}

\author{
Davide Gnocchi ${ }^{1}$, Matteo Pedrelli ${ }^{1,2}$, Eva Hurt-Camejo ${ }^{2}$ and Paolo Parini ${ }^{1, *}$
}

1 Division of Clinical Chemistry, Department of Laboratory Medicine, Karolinska Institutet at Karolinska University Hospital Huddinge, Stockholm, 14186, Sweden;

E-Mails: davide.gnocchi@ki.se (D.G.); matteo.pedrelli@ki.se (M.P.)

2 Strategy and Externalization, CVMD iMED, AstraZeneca, R\&D, Mölndal, SE-431 83, Sweden; E-Mails: Matteo.Pedrelli@astrazeneca.com (M.P.); Eva.Hurt-Camejo@astrazeneca.com (E.H.C.)

* Author to whom correspondence should be addressed; E-Mail: paolo.parini@ki.se; Tel.: +46-858589310; Fax: +46-858581260.

Academic Editor: Annette Graham

Received: 10 December 2014 / Accepted: 28 January 2015 / Published: 5 February 2015

\begin{abstract}
Disorders of lipid and lipoprotein metabolism and transport are responsible for the development of a large spectrum of pathologies, ranging from cardiovascular diseases, to metabolic syndrome, even to tumour development. Recently, a deeper knowledge of the molecular mechanisms that control our biological clock and circadian rhythms has been achieved. From these studies it has clearly emerged how the molecular clock tightly regulates every aspect of our lives, including our metabolism. This review analyses the organisation and functioning of the circadian clock and its relevance in the regulation of physiological processes. We also describe metabolism and transport of lipids and lipoproteins as an essential aspect for our health, and we will focus on how the circadian clock and lipid metabolism are greatly interconnected. Finally, we discuss how a deeper knowledge of this relationship might be useful to improve the recent spread of metabolic diseases.
\end{abstract}

Keywords: circadian clock; central oscillator; peripheral oscillators; lipid metabolism; lipid transport; metabolic diseases 


\section{Introduction}

A properly functional metabolism is one of the key factors determining our wellbeing. Metabolism and transport of lipids and lipoproteins have been deeply investigated by scientists in the past decades, and it is now widely accepted that defects in their regulation are strongly associated with the development of many pathological conditions, such as the metabolic syndrome, most cardiovascular diseases, and even tumour development [1].

The first pioneers who commenced the study of biological rhythms were not initially well considered by the scientific community. The topic was perceived too "exotic" to be worthy of consideration, and the idea of the existence of a molecular clock that oscillates autonomously, being synchronised by external stimuli such as light, was difficult to accept. Despite this initial diffidence, this subject is now drawing the interest of researchers, especially for its relevance in regulation of metabolism [2].

Here we first give an overview on the discovery of the circadian clock, and on its organisation from an anatomical and biochemical point of view. Then we will focus on the deep relationship between the circadian clock and energy metabolism, pointing to lipid and lipoprotein metabolism and transport as key determinants of our health.

\section{The Circadian Clock}

\subsection{Historical Overview}

The existence in higher eukaryotes of an internal periodicity, independent from external stimuli such as light, was long ago recognised by the French scientist Jean-Jacques d'Ortous De Mairan, in the beginning of the 18th century. He discovered that the plant Mimosa Pudica, even when closed in a wood locker without any source of light, retained the usual $24 \mathrm{~h}$ periodicity in the opening-closing cycles of its leaves [3]. About one hundred years after that discovery, in the middle of 19th century, the Swiss botanic Alphonse de Candolle, using the same plant, assessed that the leaf cycle was not constant, being slightly different from $24 \mathrm{~h} \mathrm{[4].} \mathrm{But} \mathrm{it} \mathrm{was} \mathrm{not} \mathrm{until} \mathrm{the} \mathrm{early} \mathrm{middle} \mathrm{of} \mathrm{the} \mathrm{20th} \mathrm{century} \mathrm{-} \mathrm{but} \mathrm{published} \mathrm{later-}$ that a rigorous confirmation would have come: the German scientist Erwin Bünning discovered that the leaf cycle of Phaseolus - the common bean-showed an average periodicity of $24.4 \mathrm{~h}$ [5]. Later, the British born biologist Colin Pittendrigh and his colleagues found that similarly, in Drosophila the daily cycle was not exactly $24 \mathrm{~h}$, but it oscillated between $22 \mathrm{~h}$ and $28 \mathrm{~h}$. Those findings introduced a key concept for the understanding of biological rhythms: the periodicity is not induced by external stimuli, but it is "innate", with an average period slightly different from $24 \mathrm{~h}$. This internal "pendulum" that oscillates autonomously was termed "free-running" rhythm, and the external environmental stimuli are just able to synchronise it. Light is the principal "timer" ("Zeitgeber" in German) that regulates the freerunning cycle, and the effect of synchronisation is known as "entrainment". Light synchronises mammalian circadian rhythms with the environmental time by modulating retinal input to the central nervous system (CNS), and this photic entrainment requires neither rods nor cones. In fact, retinal ganglion cells innervating the CNS are intrinsically photosensitive, and depolarise in response to light even when all synaptic inputs from rods and cones are blocked [6]. These ganglion cells are now believed to function as the primary photoreceptors for this system, since the sensitivity, spectral tuning, and kinetics of the response to the light fit with those of the light entrainment [6]. 


\subsection{The Core Clock Machinery}

Since those discoveries great progress was made in this research field, and thanks to the efforts of a few pioneers who worked on it from the middle of 1960s', we now know quite a lot of how our internal clocks are organised and how deeply rhythmic we are.

The most important breakthrough was the discovery of the anatomical localisation of the clock, and the assessment of which cells and which physiological mechanisms were involved. In 1967 it was demonstrated that after damaging the hypothalamus in rats, the animals lost most of their behavioural periodicity [7]. Just five years later, the exact site of the clock was localised to a small group of cells in the anterior hypothalamus, subsequently termed the suprachiasmatic nucleus ( $\mathrm{SCN}$ ) [8], and the neural connection linking the eye to the SCN was also clarified, and named the "retinohypothalamic tract" (RHT) [9]. The regulation of the internal periodic behavioural patterns driven by the SCN was recognised as an intrinsic physiological property of the SCN itself, namely its ability to generate a rhythmic electrical activity with a period of about $24 \mathrm{~h}$. Such an electrical oscillation in turn induced a similar pattern in the neighbour neurons, even if with a phase shift in nocturnal animals (e.g., rats) during the night [10-12].

The molecular machine responsible for the functioning of the circadian clock was unravelled after a series of experiments, using mutants of the fruit fly Drosophila. The first gene identified was named period (Per), because the mutant flies had an altered eclosion time [13]; the protein codified by this gene (PER), showed rhythmic cycles of synthesis well-coordinated with the circadian behaviour of the fly [14]. The model explaining those observations was proposed several years later, and it was based on a complex negative feedback loop, which involves, in addition to PER, three other proteins: (i) the product of the timeless (Tim) gene, TIM, also identified in Drosophila [15,16]; (ii) CLOCK, whose gene Clock, was originally identified in mice [17]; and (iii) CYCLE (CYC). The regulation is achieved through the formation of a complex CLOCK $\bullet$ CYCLE, which binds to the E-box region on the Per and Tim promoters, activating their transcription. When then levels of PER and TIM increase, the complex PER•TIM binds to CLOCK $\bullet$ CYCLE, preventing its role as a transcriptional activator until the transcription is completely abolished, and a cycle of synthesis can start again. This mechanism is further fine-tuned by the protein kinase Doubletime (DBT), which phosphorylates PER, targeting it for proteasomal degradation. DBT can phosphorylate PER only in its free form, and not when it is complexed with TIM; for this reason, only when the levels of TIM increase, the complex PER•TIM may form, and inside the nucleus its stability is about $10 \mathrm{~h}$. The entrainment by light is achieved by two different systems that perceive the luminous input, one through the photopigment cryptochrome (CRY), the other through opsin-based photopigments. Once the light has been sensed, the stimulus results in TIM degradation, which in turn will reset the whole mechanism [18].

Although the general outline of the clock is similar to that operating in Drosophila, in mice some key differences exist. Three Per homologue genes were identified until now, named mPerl-3, whose transcription is rapidly stimulated by light, with a period of about $24 \mathrm{~h}$ [19-21]. Up to now there are no clues of the existence of a gene performing the same function as Tim in Drosophila, even if the central role of one of these possible analogues in entraining the clock in cooperation with Per1/2 was suggested [22]. Interestingly, it was shown that Tim plays a key role in the regulation of developmental processes. For example, in mouse and rat embryos mTim was highly expressed in the developing lung, liver, and kidney, 
as well as neuroepithelium, strongly supporting its role in epithelial organogenesis [23]. Moreover, it was recently assessed that mTim plays a role in the regulation of apoptotic processes that coordinate the differentiation of mouse embryonic stem cells, thus corroborating the hypothesis of a deep relationship between the circadian clock and the early developmental stages in mammals [24]. The analogue of cycle was identified, and named Bmal1 in mammals [25], whereas, as described previously, clock was originally identified in mice [17]. In mammals Cry is not involved in the reception of light, but it nevertheless represents an essential part of the feedback mechanism, with both of its isoforms, Cryl and Cry2 [26-28]. The mechanism is further refined by additional components, such as $\operatorname{Rev-Erb} \alpha / \beta$ and $R O R \alpha / \beta$, which bind to the RORE enhancer element in the Bmall gene, and repress and stimulate its transcription respectively. Though previously believed not fundamental for the generation of circadian rhythmicity [29-32], they were recently recognised to play a more important structural role in the overall functioning of the clock machinery [33]. Finally, the role of DBT in Drosophila is achieved in mammals by casein kinase $1 \varepsilon$ $(\mathrm{CK} 1 \varepsilon)$ and casein kinase $1 \delta(\mathrm{CK} 1 \delta)$, which together $(\mathrm{CK} 1 \delta / \varepsilon)$ phosphorylate PER proteins, addressing them to proteasomal degradation [11,34-36]. Thus, the overall process in mammals starts after the light is sensed by the specific photoreceptor melanopsin, which is localised in the retinal ganglion cells forming the RHT tract and projecting to the SCN [6,37-39]. This stimulus triggers a chain of responses that in turn reset the clock by the increase of transcription of mPerl-3. The de novo synthesised PER proteins, after binding to CRY, enter into the nucleus, and this PER•CRY complex is able to inhibit the transcription of the clock controlled genes (ccg) and of their own genes, usually activated by the binding of CLOCK•BMAL1 to the E-box enhancer elements [40,41].

As mentioned before, an additional checkpoint is represented by $\mathrm{CK} 1 \delta / \varepsilon$-driven phosphorylation of PER $\bullet$ CRY, which targets the complex for degradation by the proteasome. It was determined that CLOCK has a histone acetyltransferase (HAT) activity, and its heterodimeric partner BMAL1 enhanced HAT function. This HAT activity of CLOCK was essential to restore circadian rhythmicity and the activation of circadian genes in Clock mutant cells [40]. CLOCK was also able to acetylate BMAL1, which underwent rhythmic acetylation in mouse liver, with a timing that parallels the down-regulation of circadian transcription of clock-controlled genes. BMAL1 acetylation facilitated recruitment of CRY1 to CLOCK $\cdot \mathrm{BMAL} 1$, thereby promoting transcriptional repression. Thus, this enzymatic interplay between the two clock components is fundamental for the functioning of the circadian clock machinery [41]. Figure 1 gives a schematic overview of the molecular organisation of the circadian clock and of its main outputs on the regulation of metabolic pathways. The effect of variations of metabolic flux on the circadian machinery is also represented. The role of SIRT1, NAD ${ }^{+}$ and AMPK will be extensively discussed in Section 4 of this review.

The circadian activity generated in the $\mathrm{SCN}$, needs to be transmitted to the rest of the brain and henceforth to the rest of the body. The SCN is able to transmit signals in two principal ways: (i) neuronal networking, by directly interacting with several other brain structures (ii) chemically, by producing diverse signalling molecules. As far as the physical interactions are concerned, the SCN connects directly with the subparaventricular zone (sPVZ) [42], the preoptic area (POA), the bed nucleus of the stria terminalis (BNST), the lateral septum (LS), the dorsomedial hypothalamus (DMH), the arcuate nucleus (ARC), and the paraventricular nucleus (PVN) [43]. The signal from the SCN to the above-mentioned structures is communicated through classical neurotransmission, mediated by GABA and glutamate [44]. The SCN is also able to produce itself a repertoire of signal molecules, 
which in turn act on neighbouring structures. Among the best characterised until now there are arginine vasopressin (AVP) [45], vasoactive intestinal peptide (VIP) [46], cardiolipin-like cytokine [47], prokineticin 2 (PK2) [48], and transforming growth factor $\alpha$ (TGF $\alpha$ ) [49,50].

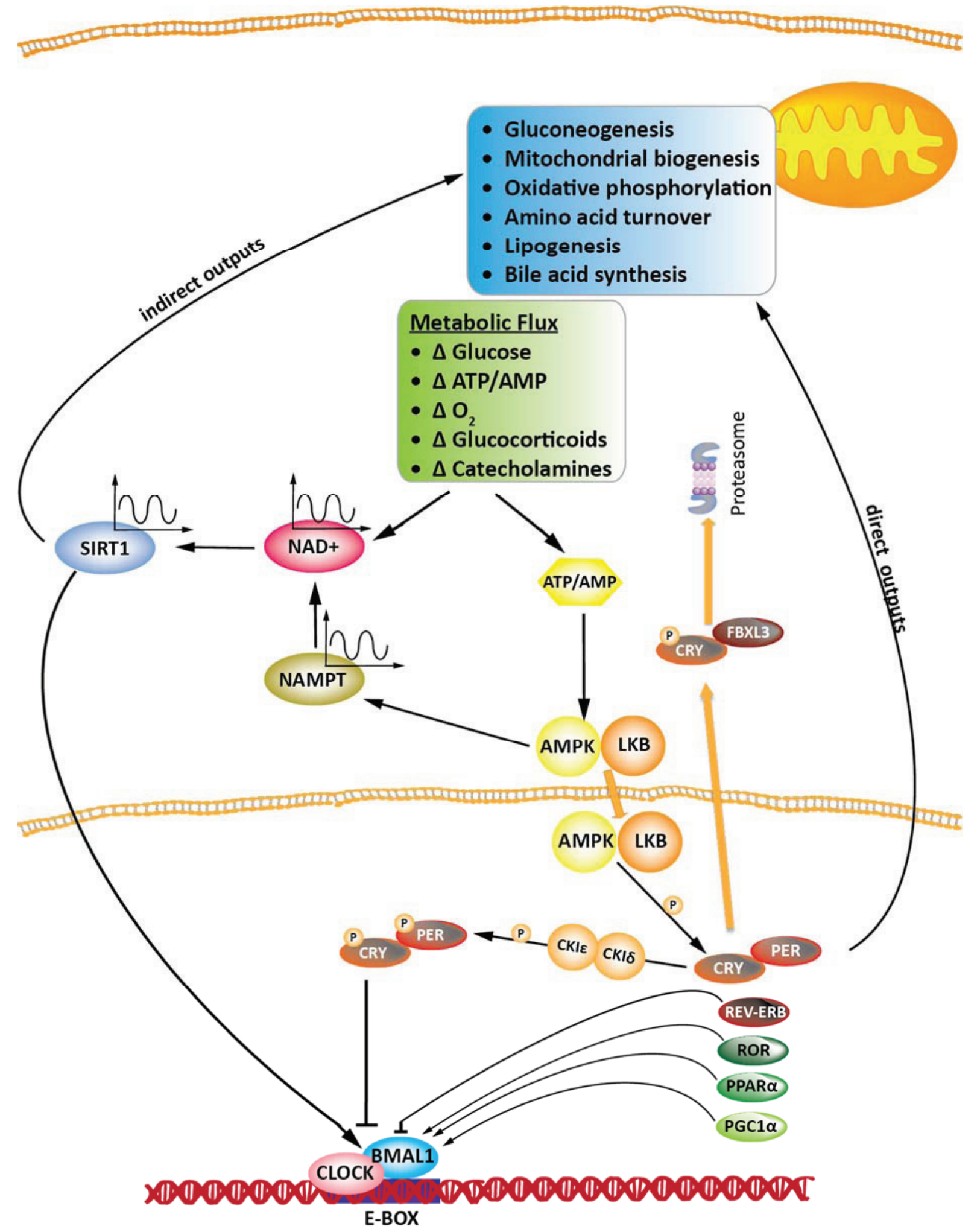

Figure 1. Schematic drawing representing the molecular machine that regulates the circadian clock and its interplay with metabolism. Waves symbolises circadian regulation. NAMPT: nicotinamide phosphoribosyltransferase. See text for details. 


\subsubsection{SCN as a Regulator of Hormonal Homeostasis}

One of the first and best-characterised interactions of SCN is with the pineal gland through the sympathetic neurons of the superior cervical ganglion [51]; in turn, the rhythmic activity of the SCN determines the release of melatonin, which directly correlates with the day length. This communication is very important in the regulation of secretion of several key hormones, such as gonadotropin- releasing hormone $(\mathrm{GnRH})$, luteinising hormone $(\mathrm{LH})$, and the follicle-stimulating hormone (FSH) [52]. Melatonin is involved in the regulation of circadian and circannual rhythms in all tissues and hence, from several points of views it can be regarded as a real "zeitgeber". Synthesis of melatonin also occurs in peripheral tissues, such as the gastrointestinal tract, the retina, skin, lymphocytes and bone marrow, from which it may in turn influence other physiological functions through paracrine signalling. Indeed, melatonin was shown to affect diverse physiological functions, such as regulation of blood pressure [53], modulation of the immune system and free radical scavenging [54].

The circadian activity of the SCN directly affects the rhythmical secretion of several other key hormones. Arginine vasopressin (AVP), or simply vasopressin, produced in the pituitary gland, is able to affect water balance, by decreasing its elimination from kidneys to prevent dehydration. The SCN directly regulates its circadian liberation into the cerebrospinal fluid [55], and as reported before, AVP is produced by the SCN itself, where it is essential for the synchronisation of the neuronal activity [56]. The other key molecule that shows a circadian pattern of release is the neurotransmitter acetylcholine (ACh) [57], which in addition to the well-known effects on muscle contraction and gluconeogenesis, is also able to play a role in the regulation of the firing activity of the SCN, acting through a muscarinic ACh receptor [58]. The periodic release of glucocorticoids from the adrenal cortex is also orchestrated by the SCN, which determines the maximal output in the early morning for diurnal animals and in the early evening for the nocturnal ones [59,60]. Adrenocorticotropic hormone (ACTH) displays a similar pattern of release from the corticotrope cells of the pituitary, and in turn stimulates the release of corticosterone from the adrenal cortex [59]. Remarkably, this process is repressed by light, and it seems to be directly dependent on SCN, through its connections to the paraventricular nucleus [59]. This accurate control is very important considering the central roles played by this hormone, both as a precursor of aldosterone and for its regulation of liver metabolic functions, hence behaving as a glucocorticoid [61]. Notably, the glucocorticoid receptor agonist dexamethasone is able to synchronise circadian gene expression in rat fibroblasts in vitro and to shift the phase of expression of circadian genes in liver, kidney, and heart; moreover, due to the absence of glucocorticoid receptors in the SCN, dexamethasone does not change its circadian behaviour [62].

\subsection{Peripheral Clocks}

In addition to being present centrally in the SCN, the machinery responsible for the generation of the circadian activity is expressed in almost all the peripheral tissues, as recently revealed in rodents $[63,64]$. This peripheral periodicity was dependent on the activity of the central oscillator, for it attenuated until stopping without the contribution of the SCN after 2-7 cycles in liver, lung and skeletal muscle in vitro [63]. However, a successive study reported that peripheral tissues were capable of self-sustained circadian oscillations for $>20$ cycles in isolation. In addition, peripheral organs expressed tissue-specific 
differences in circadian period and phase, and lesions of the SCN did not block circadian rhythmicity, but instead just desynchronized the peripheral tissues of individual animals and from different animals. So, peripheral organs express at least a partially self-sustained circadian oscillator [64]. Such circadian behaviour was shown also in vitro in several cell types [65-68], and in tissue explants from almost all organs $[64,69]$. Interestingly, the brain itself possesses its own circadian oscillation in the expression of several genes that seems to be independent of the activity of the SCN, at least according to what was shown in the olfactory bulb [70-72].

About $2 \%$ to $10 \%$ of the whole genome showed a circadian pattern of expression in several tissues as measured in mice [73-76]. Some of these genes were expressed in a tissue-specific manner, but the vast majority was common for almost all tissues; the genes implicated in the periodicity - as for example Per2, Bmal1, Rev-erb $\alpha$ and Cry — displayed the highest degree of conservation [77].

\subsubsection{Entrainment of Peripheral Clocks}

The peripheral clocks are synchronised by three main sources of entrainment: (i) direct entrainment through neural and hormonal signals (controlled by the SCN); (ii) food entrainment; and (iii) body temperature entrainment.

Neural control is achieved through the autonomic nervous system, whose outputs are in turn indirectly controlled by the SCN. For example, in SCN-deficient rats, the light did not drive the sympathetic-induced release of corticosterone by the adrenal gland [78]; analogously, in rats without the SCN, the hyperglycaemic effect of GABA antagonists was lacking [79]. In rats whose autonomic liver innervation was surgically impaired, the light did not induce the upregulation of Per 1/2, Pepck and Glut2 [80]. This finding further supports the key-role of the autonomic nervous system.

The activity of the SCN is also able to regulate the secretion of several essential hormonal mediators, such as AVP, Ach and glucocorticoids, as discussed previously in Section 2.2.1.

Food exerts an important entrainment role in several peripheral organs, such as heart, kidney, pancreas and liver, as we will examine in a more detailed way in the following sections. In the mouse liver most of the genes that cycle in a circadian way were directly involved in the regulation of metabolic pathways [81,82], similarly to what was observed in the heart [74]. In the liver and in lung fasting-feeding cycles operate strongly in the synchronisation of the peripheral clock. In rats, which typically have a nocturnal feeding behaviour, the inversion of feeding cycles - thus artificially inducing a diurnal eating - rapidly and extensively changed the hepatic expression of metabolic genes; rhythmicity in the lung was also slightly affected [83]. Importantly, the SCN seems to play a multifaceted role in the time-setting of the different peripheral organs, as was clarified in mice with damaged SCN. These animals still showed a regular periodicity in liver and kidney, but not in skeletal muscle, heart and spleen [84]. These findings further underline the complexity of the system, and the interplay between different regulatory mechanisms. Moreover, in Cry1/2-deficient mice a temporally restricted feeding protocol was able to restore the circadian transcriptional periodicity of the vast majority of the hepatic genes. Conversely, without a fixed schedule in feeding, the animals kept the transcriptional periodicity of just the minor part of the usual circadian-expressed genes [8]. The regulation of circadian rhythms in peripheral tissues by feeding/fasting is achieved also through the release of hormones such as peptide YY, oxyntomodulin, cholecystokinin, leptin, and ghrelin, which directly signal to the neurons of the paraventricular nucleus (reviewed in [85]). The extent of the 
association of the SCN in this regulation and the mechanisms involved are still under investigation; however it was demonstrated that when the SCN was damaged the circadian patterns of feeding and drinking were abolished [8,86].

The third important factor for the regulation of the circadian clock in the peripheral tissues is temperature, even if the mechanisms involved are up to now not fully understood. The SCN itself is able to compensate temperature variations of the external [87-89] and internal environment [87]; this process seems to be mediated by CRY and PER [90,91]. On the other hand, the SCN activity regulates daily changes in body temperature [92], and these changes in turn were shown to keep the peripheral clocks synchronised [89]. In Drosophila, in addition to light, temperature mediated the interaction between CRY and the complex PER -TIM. Heat-induced phase shifts were severely reduced in cry loss-of-function mutants, and per mutants showed a significant enhanced temperature sensitivity of biochemical interactions and behavioural phase shifting. Light and temperature acted together to affect the rhythms in wild-type flies through similar mechanisms, since the interaction between CRY and the complex PER•TIM was central for circadian responses to both light and temperature variations [90]. Thus, working synergistically to orchestrate the circadian phase, light and temperature could fine-tune the regulation of the clock, hence contributing to the seasonal adaptations of clock function [90].

\subsubsection{Liver and Pancreas Clocks}

The liver is a key organ in the control of lipid and glucose homeostasis, bile acid synthesis, and cholesterol, amino acids and xenobiotic metabolism [74,75,93]. As already mentioned in the previous sections, the levels of expression of hepatic genes follow a circadian periodicity, for both clock-related and hepatic-specific genes. The circadian genes seem to be fundamental for the preservation of the liver functions, as demonstrated in Bmall-deficient mice, which lost their rhythmical behaviour either in brain and in the liver, and in Clock-deficient mice, whose hepatic circadian clock was abolished but still retained central periodicity $[17,75]$. Nonetheless, liver periodicity seems to possess a relative autonomy from the central regulator, as assessed in mice; in fact, here the glucocorticoid receptor - a powerful transcriptional activator-was able to rescue about $60 \%$ of the circadian gene expression that was shut off by damaging the SCN [61]. Moreover, the liver oscillator is strongly dependent upon food for tuning, even if the central pacemaker is correctly working, as more than the $80 \%$ of the hepatic transcriptome is "meal-dependent" [8].

The pivotal role of the circadian oscillator in the regulation of glucose metabolism was revealed in Bmall-deficient mice. Here the liver-specific inactivation of Bmall resulted in severe hypoglycaemia during their inactivity period, but not if Bmall was inactivated in all the other cell types excluding the liver; comparable results were obtained after inactivation of Per1/2 [94]. From what has emerged from a recent study, Per 2 plays a role in the regulation of glucose homeostasis also in humans [95].

In mice, the regulation of bile acid and cholesterol biosynthesis is under circadian control through Rev-Erb $\alpha$, which regulates the expression of SREBP, and consequently that of cholesterol metabolism genes. It was also supposed that the cyclic expression of cholesterol-7 $\alpha$-hydroxylase (Cyp $7 a 1)$ might be driven by a REV-ERB $\alpha$ mechanism, by means of an oxysterol-mediated LXR activation [96].

The role of the pancreas in maintaining the glucose balance is well known, and recently the presence of an independent circadian oscillator, essential in driving the proper functioning of 
pancreatic functions, was clarified [97,98]. The fundamental role is played by Bmall and Clock, whose selective knockdown in mice led to modifications of the proliferative rate and size of islet cells, together with hypoinsulinaemia, reduced glucose tolerance and diabetes. Remarkably, in the same mouse system, the re-establishment of the pancreatic islet function results in an improvement of the insulin resistance, but not of obesity [99].

\section{The Circadian Clock in Lipid Metabolism and Transport}

\subsection{Circadian Regulation of Triglycerides Levels}

Evidences showing that the levels of triglycerides in the plasma oscillate following a circadian pattern were provided long ago in both humans [100] and rodents [101], in these latter with a maximum during their activity phase. In humans two separate spikes in plasma triglycerides levels were identified: the first, smaller, around eight hours after arousal, and the second about 20 hours after awakening. Desynchronisation of the sleep schedule did not affect the appearance of the first peak, but resulted in the loss of the second one. It was thus hypothesised that the first one was mostly dependent upon an endogenous circadian regulation, and the second probably more finely-tuned by the sleep cycles [102]. By means of a metabolomic approach [103], it was demonstrated that in humans around 15\% of all the small molecular weight metabolites taken into account showed circadian variations and among them more than $75 \%$ were lipids, mostly fatty acids. From this work it emerged that the endogenous circadian clock is the principal regulator of these fluctuations in the plasma lipid profile, as changes in the sleeping or feeding schedule could not affect this pattern [103]. A successive study shed light on which was the chemical nature of the cycling fatty acids in the plasma, and the major part was constituted by diacylglycerols and triacylglycerols [104].

Several lines of evidence have shown that the molecular clock is directly involved in the control of lipogenesis. Mice with a mutated Clock gene were prone to develop hypertriglyceridaemia [105], and this was later ascertained to be primarily due to effects at the liver and enterocyte level [106]. A key role in the regulation of lipid metabolism was determined for Nocturnin, a gene expressed in a circadian manner, whose product is an enzyme with a deadenylase activity. Nocturnin-deficient mice on a high-fat diet did not increase their body weight and visceral fat, and did not develop fatty liver, without increasing their activity rate or decreasing food intake. The authors suggested that Nocturnin could affect lipid metabolism or uptake, together with glucose and insulin sensitivity [107]. Clock-deficient mice displayed also a reduced hepatic triglyceride accumulation under high-fat diet conditions, due to the suppressed expression of the two key genes Acsl4 and Fabpl [108].

\subsection{Circadian Regulation of Lipid Transport}

\subsubsection{Periodicity in the Intestine}

Similarly to the organs described previously, the intestine shows a circadian periodicity in several of its functions, such as DNA synthesis, epithelial cell renewal, electrolyte and food absorption, food-anticipatory activity, motility [109-113]. In rodents, the maximal expression of clock-related genes was observed during the day in both the colon [110,114] and the jejunum [112]; these spikes were coordinated with those present in the liver, but phase-shifted with respect of those in the SCN [83]. 
In humans, deleterious effects on gastrointestinal functions were reported due to periodic or chronic sleep deprivation or disturbances, as well as to periodic misalignment of the circadian rhythm, as it occurs in frequent long trans-meridian voyages [115]. The spectrum of the pathologies described is wide, including peptic ulcer, gastro-oesophageal reflux and irritable bowel syndrome, up to risks of polyps and colorectal cancer [116].

\subsubsection{Lipid Transport: A Short Overview}

The digestion of the main dietary lipids, i.e. cholesterol esters, phospholipids and triglycerides, takes place in the intestinal lumen, where they are emulsified by bile salts and incorporated into bile salt micelles $[117,118]$. Triglyceride digestion begins in the mouth by means of salivary lipases, then follows in the stomach by gastric lipases, and is finished in the small intestine by pancreatic lipases, whose enzymatic activity produces free fatty acids (FFAs) and monoacylglycerols. Pancreatic phospholipases are the main phospholipid-hydrolysing enzymes, and among them phospholipase A2 is the principal one, which produces FFAs and lysophospholipids; likewise, cholesterol esterases produce FFA and free cholesterol. The absorption of FFAs and monoacylglycerols into the enterocyte takes place by diffusion or by means of protein transporters such as clusters of differentiation 36 (CD36). Several cholesterol transport proteins have been identified up to now, such as Niemann-Pick C1-like 1 (NPC1L1), scavenger receptor B1 (SRB1), and CD36. All these aspects have been extensively reviewed [119].

The processing of FFAs follows in several organelles, but principally inside the endoplasmic reticulum (ER), where they are transported by means of specific FA-binding proteins. The ER has all the enzymatic activities needed to synthesise phospholipids, cholesterol esters and triglycerides. Phospholipids and triglycerides are synthesised from monoacylglycerols through different pathways. Inside the enterocyte, monoacylglycerol acyltransferase synthesizes diacylglycerol (DAG) from FFA, and monoacylglycerol and diacylglycerol acyltransferases (DGATs) release triglycerides. On the other hand, ethanolamine and choline transferases are mainly responsible for phospholipid biosynthesis from ethanolamine and choline, and DAG. The esterification of free cholesterol is performed by an acyl-CoA:cholesterol acyltransferase [119].

Then lipids are packed inside the chylomicrons (CMs), which usually contain phospholipids, mainly on the surface, and triglycerides and cholesteryl esters in the central part. On the surface there are also several scaffolding proteins, named apolipoprotein (Apo); the main Apo component in CMs is ApoB48, together with ApoC, ApoAI and ApoAIV [119,120]. The translation of ApoB48, which takes place on the ER membrane, is stringently dependent upon the presence of microsomal triglyceride transfer protein (MTP) and of a sufficient amount of lipids. MTP transfers TG to ApoB, helping the formation of a folding structure more favourable to store large amounts of lipids [119,121]. This pathway leads to the production of an "HDL-like" chylomicron, which is first provided with phospholipids and neutral lipids externally, and henceforth is loaded with newly synthesised triglycerides and cholesteryl esters (CE) [119,122,123].

Along with triglycerides, CMs carry also relevant amounts of cholesterol; however, free cholesterol can be also transported back to the intestinal lumen by means of the ATP-binding cassette G5 and 8 (ABCG5 and ABCG8), and can be secreted from the basolateral side through the HDL pathway, which involves ApoAI and ABCA1 [124,125]. This transporter plays a very important role for cholesterol transport through the HDL pathway, even if it is not involved in the CMs pathway [126]. 


\subsubsection{Circadian Influence on Lipid Absorption and Transport}

In mice lipid absorption at the enterocyte level was higher during the night and lower during the day $[112,127-129]$. Two studies reported circadian oscillations in the uptake and secretion of fatty acids (FAs) and cholesterol, contextually showing the same rhythmical pattern in the mRNA levels of several of the proteins involved in such processes, such as stearoyl-CoA desaturase-1 (SCD-1), fatty acid synthase (FAS), DGAT2, MTP, ApoB and ApoAIV [127]. The expression of these genes was food-entrainable, and the authors also suggested that the genes involved in lipid absorption could be classified as light responsive, food responsive, light and food responsive, and nonresponsive [112].

Clock plays a pivotal role in controlling several steps of these processes. Circadian rhythm genes were normally expressed in the enterocytes with the usual circadian pattern that is also food-entrained; this regulation was completely lost in clock-mutant mice whose food clock regulation was impaired $[127,128]$. This mouse genotype showed hypertriglyceridaemia that was mainly associated to their increased lipid absorption during the day; in contrast, wild type animals had the peak of absorption in the middle of the night $[112,127,128]$. Clock-mutant mice were utterly lacking the circadian regulation of Mtp expression, which resulted in a nadir of transcription in the middle of the day and in a zenith in the middle of the night. Such a loss of regulation was mainly due to the missed control of the normal diurnal Clockinduced repression of the Mtp gene, which is usually achieved by means of the synthesis of the transcriptional repressor SHP (small heterodimer partner). Due to this missed Mtp repression, clockmutant mice showed a high MTP expression, an increased production of triglyceride-rich lipoproteins and a sustained hypertriglyceridaemia [128].

Clock is very important in the regulation of cholesterol metabolism as well, for Clock-/ApoEdouble mutant mice were hypercholesterolemic, due to the accumulation of ApoB48-containing cholesteryl ester-rich lipoproteins, and the increased intestinal cholesterol absorption contributed further to hypercholesterolemia. In Clock-/-ApoE-/- mice intestinal expression of Niemann-Pick C1Like 1 (NPCL1), Acyl-CoA:Cholesterol acyltransferase 1 (ACAT1) and MTP was elevated and the enterocytes assembled and secreted more CMs. Moreover, a macrophage dysfunction was identified as another possible cause of increased atherosclerosis in such double-mutant mice, since they absorbed more lipids if compared with the ApoE mutants, and cholesterol efflux from macrophages was impaired, due to the reduced expression of ABCA1 [129].

In humans under a standard diet regimen, apoB48 showed a diurnal variation with three distinct spikes, the first around 10:00 a.m., the second at about 14:00, the last between 18:30 and 19:00. ApoB100 did not show any variation, not even after a fat load, suggesting that its synthesis is not subjected to entrainment by food [130].

\subsubsection{Circadian Control of Lipid Biosynthesis}

Circadian genes do not only control lipid absorption, but are also involved in the regulation of lipid biosynthesis. It was long ago observed in rodents that cholesterol synthesis showed a circadian pattern in the liver and in the intestine, being higher during the night and lower during the day [131-138]. This regulation was mainly achieved through the circadian expression of $\beta$-hydroxy-3-methylglutaryl-CoA reductase (HMG-CoA reductase) and of Cyp7A1 [131-135,139]. Together with light entrainment, 
cholesterol biosynthesis and $H M G-C o A$ reductase expression appeared to be strongly entrained also by food ingestion, as shown in several rodent models in both the intestine and the liver [133-135,140], and also in a human study [141]. In rodents bile acid (BA) profile followed a circadian periodicity in the serum, liver, gallbladder and intestine; the zenith and nadir of these fluctuations were the opposite of those observed for cholesterol biosynthesis in the serum and intestine, but not in the liver and gallbladder $[142,143]$. In one human study, BA synthesis respected a circadian schedule, with two main peaks during the day, one around 1 p.m., the other round 9 p.m. On the other hand, the circadian rhythm of cholesterol biosynthesis showed a nocturnal peak, between 12 and 4 a.m., exactly the opposite of what was described in rodents. The patients involved in the study had primary endogenous hypertriglyceridaemia, and were kept on a carbohydrate-rich diet (meals at 9:00, 13:00 and 17:00 h). Serum TG showed a wavelike pattern with the maximum at around 17:00 h, differently to normal subject that peaked at around 14:00 $\mathrm{h}$. In the fasting state, the activity of lipoprotein lipase (LPL) was not different from that observed in healthy subjects, but did not show the normal rise in the fed state $(16: 30 \mathrm{~h})$. This was determined by the missed increase in the activity of the adipose tissue (AT)-LPL during the day, which was always lower than in normal subjects. LPL activity in skeletal muscle was always low, without any diurnal change. Low-density lipoprotein cholesterol and high-density lipoprotein (HDL) cholesterol concentrations did not vary during the day, but HDL phospholipids showed a significant increase during the day [144]. In mice, the diurnal variations of BA concentrations and composition might play important roles in coordinating daily nutrient absorption and energy homeostasis. This regulation was achieved by influencing the circadian rhythms of expression of BA metabolising genes in the liver and ileum and of enterohepatic genes encoding key proteins involved in BA biosynthesis and transport [145]

The levels of several key proteins implicated in the regulation of triglyceride metabolism — such as lipolytic enzymes, ApoAIV and PPAR $\alpha$ - oscillated with a circadian periodicity, both in rodents and humans [137]. In mice fatty acid synthase (FAS), acetyl-CoA carboxylase (ACC), SREBP1c, and fattyacid-binding protein 4 (FABP4) fluctuated in a circadian way in both adipose tissue and liver $[108,146]$.

Several authors have recently supported a pivotal role of Clock in the regulation of both cholesterol and triglyceride metabolism. In wild-type mice, the hepatic circadian regulation of $H M G-C o A$ reductase, low-density lipoprotein receptor $(L D L r)$, and $C y p 7 A 1$ was dampened and finally abolished after four weeks under a cholic acid diet. Clock-mutant mice, on the other hand, in addition to an unscheduled expression of clock-genes, such as Bmal1 and Per2, showed also an arrhythmic expression of $H M G-C o A$ reductase, $L D L r$ and Cyp7al. Moreover, when fed with a high cholesterol+cholic acid diet, these mice displayed a remarkable cholesterol accumulation in the liver and a reduced expression of Cyp7al with respect to wild-type mice [147]. Clock-mutant C5B1/6J mice were obese and showed all the typical characteristics of metabolic syndrome, such as hyperglycaemia, hypertriglyceridaemia, hypercholesterolemia and hypoinsulinaemia [105]. Differently, in Clock-mutant ICR mice, serum levels of triglycerides and free fatty acid were significantly lower than in wild-type control, whereas total glucose and cholesterol levels were unchanged. Likewise, in homozygous Clock-mutant mice the increase in body weight induced by a high-fat diet was reduced, and dietary fat absorption was severely impaired. Interestingly, in the pancreas of Clock-mutant mice, circadian expression of cholecystokinin-A (CCK-A) receptor and lipase mRNAs was greatly reduced [148]. The role of Clock in the regulation of the lipid metabolism seems thus to be quite complex, with several points that need to be clarified in the future. 
Clock was not only able to affect deeply the regulation of triglyceride and cholesterol metabolism, but high fat feeding and metabolic alterations influenced its expression. C5B1/6J mice on a high-fat diet showed a reduced circadian pattern of expression of clock and clock-controlled genes in the adipose tissue and in the liver [146]. On the contrary, ICR mice fed a high-fat diet displayed symptoms of metabolic syndrome with hyperglycaemia, hyperlipidaemia and obesity. Nonetheless, the high-fat feeding was almost ineffective in changing the rhythmic expression of the clock genes examined (Clock, Bmal1, Per1, Per2, Cry1, Cry2) in both the liver and visceral adipose tissue. Mice on high-fat diet, however, completely lost the circadian control of the expression of Cyp7A1. High-fat feeding and mild metabolic syndrome seemed thus to not directly affect the molecular clock system, but instead to interact with the circadian expression of metabolism enzymes [149]. Again, more studies will be required to clarify how fat accumulation and metabolic diseases are able to interfere with the circadian clock machinery.

Some light was recently shed on the deep relationship between the circadian clock machinery and lipid metabolic pathways. BMAL1 turned out to be a key factor in the regulation of adipogenesis and lipid metabolism in mature adipocytes, and it is also important for adipocyte differentiation, since Bmall knockout mice embryonic fibroblasts failed to differentiate into adipocytes. Bmall expression in 3T3-L1 adipocytes triggered the expression of several lipogenic factors, as the promoter activity of these genes was stimulated in a BMAL1-dependent manner. The expression of these factors was clearly circadian in mice adipose tissue, and the overexpression of BMAL1 increased lipid biosynthesis [150]. The circadian clock was also directly involved in the regulation of the expression of the transcriptional regulator Spot14, which controls the genes implicated in fatty acid synthesis, being activated in response to lipogenic stimuli. Hepatic levels of Spot14 mRNA peaked at the early dark period, the usual rodent feeding-time. Under fasting, the concentration of Spot14 mRNA was commonly diminished, but the periodicity was still retained, implying both a nutritional- and circadian clock-mediated entrainment. The circadian expression of Spot 14 was kept also under constant darkness and the rhythmicity was absent in Clock mutant mice. Hence, a synergy between the light entrainable and the food entrainable oscillators, and food-derived nutrients, controlled the circadian expression of Spot 14 in the liver [151].

The transcriptional coactivator peroxisome proliferator-activated receptor-gamma coactivator $1 \beta$ (PGC-1 $\beta$ ), plays a central part in the control of the expression of several nuclear-encoded genes regulating mitochondrial and metabolic functions in multiple tissues-including brain, brown adipose tissue, skeletal muscle, heart and liver-but is also involved in the proper functioning of the circadian machinery. In fact, in contrast to $P g c-1 \alpha \mathrm{KO}$ mice that were hyperactive, $P g c-1 \beta \mathrm{KO}$ mice displayed a significantly decreased activity during the dark cycle [152]. The nuclear receptor REV-ERB $\alpha$, which is directly involved in the control of circadian rhythms, similarly plays a regulatory role in lipid metabolism and adipogenesis, and in the control of BA metabolism through the regulation of the neutral bile acid synthesis pathway. Rev-erb $\alpha$-deficient mice showed a lower synthesis and an impaired excretion of BA into the bile and faeces, and a decreased hepatic expression of Cyp 7A1 [153].

PER2 was likewise involved in the regulation of lipid metabolism and it directly repressed Ppar $\gamma$ expression, a nuclear receptor critical in adipogenesis, insulin sensitivity, and the inflammatory response. Per2-deficient mice had altered lipid metabolism with a severe reduction of total triglycerides and non-esterified fatty acids; PER2 blocked PPAR $\gamma$-mediated transcriptional activation 
by impeding recruitment to target promoters. Per2-deficient cultured fibroblasts showed enhanced adipocyte differentiation, and lipidomic-profiling studies demonstrated that it was required for normal lipid metabolism in white adipocyte tissue [154]. The existence of more structured machinery behind the circadian regulation of lipid metabolism was very recently suggested. In this study a broad lipidomic analysis of hepatic tissue from Perl/2 null mice revealed that around the same amount of lipids (about 17\%) oscillated both in the mutant and in the wild-type mice, but following different phases and with different ratios between the oscillating species. Interestingly, several key enzymes of triglyceride metabolism were expressed in a circadian manner, even in Perl/2 mutants, and the feeding time played a central role in orchestrating the daily triglyceride metabolism both in the mutant and in the wild-type mice. Thus, it is plausible to suppose that more complex systems work in the regulation of daily triglyceride profile [155].

Figure 2 summarises what has been analysed in detail in text about the interplay between the central and peripheral circadian clocks, underlining the genes under circadian control in the liver and intestine.

\section{Circadian Clock in the Regulation of Cellular Metabolism: SIRT1, AMPK, PGC-1a, cAMP}

In the last two decades understanding of the mechanisms that govern the internal periodicity of higher organisms was greatly improved, and now we understand more in depth the circadian basis by which metabolism is regulated [156-159]. New interesting avenues have been recently opened that expand the intermingling between the regulation of metabolism and our molecular clock.

A central role in this sense was addressed to SIRT1, a member of the SIRTs family of histone deacetylases, whose activation has been associated with panoply of beneficial effects as a positive regulator of metabolic homeostasis [160]. SIRT1 is a class III histone deacetylase whose enzymatic activity, differently to that of class I and II, depends upon the presence of $\mathrm{NAD}^{+}$as a cofactor; hence, during fasting, when the concentration of $\mathrm{NAD}^{+}$is increased, the activity of SIRT1 is elevated [161]. SIRT1 was shown to directly modulate the rhythmic expression of several circadian controlled genes. Systematic $\mathrm{NAD}^{+}$-dependent deacetylation by SIRT1 of histones, BMAL1, and finally PER2 facilitated the establishment of a repressive chromatin state [162]. Moreover, the HDAC activity of SIRT1 was regulated in a circadian manner, linked with the rhythmic acetylation of BMAL1 and histone $\mathrm{H} 3$ at circadian promoters. SIRT1 associates with CLOCK and is recruited to the CLOCK•BMAL1 chromatin complex at circadian promoters, and the genetic ablation of Sirt1 or pharmacological inhibition of SIRT1 activity resulted in disruptions of the circadian cycle and of the acetylation of $\mathrm{H} 3$ and BMAL1: hence SIRT1 might function as a controller of circadian machinery, detecting changes in cellular metabolites [163]. Interestingly, intracellular $\mathrm{NAD}^{+}$levels exhibited circadian oscillations, due to the circadian expression of NAMPT (nicotinamide phosphoribosyltransferase) mediated by CLOCK $\bullet$ BMAL1 [164]. SIRT1 was therefore recruited to the Nampt promoter, controlling the circadian synthesis of its own coenzyme [167]. Finally, SIRT1 was necessary for circadian transcription of several key clock genes, such as Bmal1, Per2, Cryl, and Ror $\gamma$. SIRT1 bound CLOCK $•$ BMAL1 in a circadian manner and promoted the deacetylation and degradation of PER2. Since its deacetylase activity is dependent upon NAD ${ }^{+}$levels, SIRT1 probably acts as a molecular link between cellular metabolism and the circadian fundamental machinery (Figure 1) [165]. 


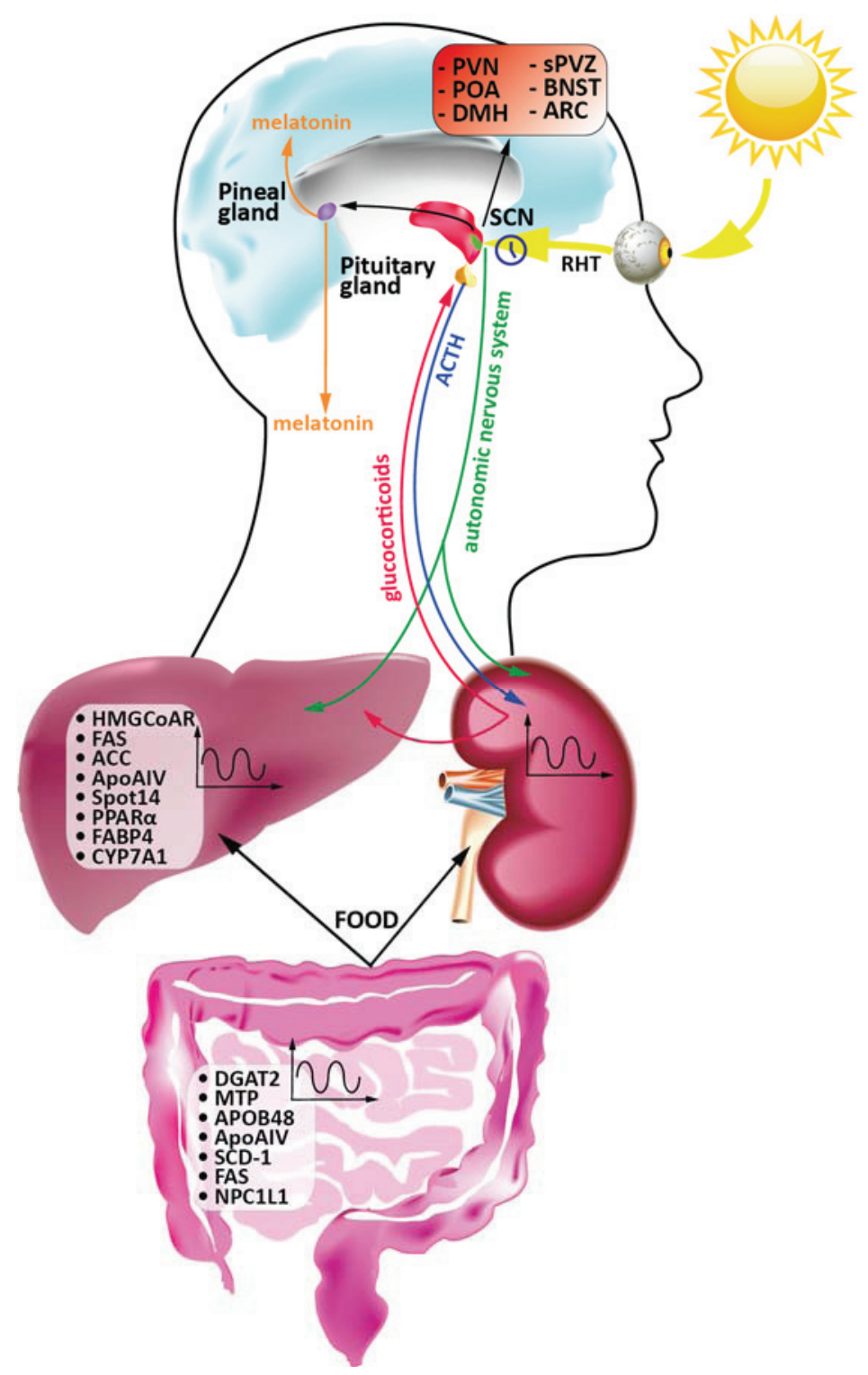

Figure 2. Schematic overview of the interplay between the central and peripheral circadian clocks. Waves symbolises circadian regulation. RHT: retinohypothalamic tract; SCN: suprachiasmatic nucleus; sPVZ: subparaventricular zone; POA: preoptic area; BNST: bed nucleus of the stria terminalis; ARC: arcuate nucleus; $\mathrm{DMH}$ : dorsomedial hypothalamus; PVN: paraventricular nucleus; ACTH: adrenocorticotropic hormone; HMGCoAR: HMG-CoA Reductase; FAS: Fatty Acid Synthase; ACC: acetyl-CoA carboxylase; ApoAIV: apolipoprotein AIV; FABP4: fatty-acid-binding-protein 4; CYP7A1: cholesterol-7 $\alpha$ hydroxylase; DGAT2: diacylglycerol acyltransferase 2; MTP: microsomal triglyceride transfer protein; SCD-1: stearoyl-CoA desaturase-1; NPC1L1: Niemann-Pick C1-like 1. See text for details.

AMPK is key multi-protein complex shown to be deeply involved in the regulation of metabolism as a general activator of catabolic pathways - glucose uptake, glycolysis, fatty acid oxidation - and inhibitor of anabolic ones - fatty acid and cholesterol biosynthesis. Recently, its direct association with the regulation of the circadian clock was demonstrated, since it is itself subjected to circadian oscillations. One of its regulatory subunits, ampk $\beta 2$ (PRKAB2), showed a circadian expression, which 
resulted in a periodic translocation in the nucleus, where it directly phosphorylated CRY1 in association with LKB kinase. Such phosphorylation results in the interaction between the phosphorylated CRY1 and the cofactor FBXL3; the complex is finally degraded into the proteasome (Figure 1) [166]. Among other recently identified mediators of the circadian control of energy metabolism, the transcriptional coactivator PGC- $1 \alpha$ plays an important role. PGC- $1 \alpha$ is generally involved in the activation of catabolic pathways, and it is activated by several stimuli, interestingly also by SIRT1 and AMPK. PGC-1 $\alpha$ was found to be rhythmically expressed in the liver and skeletal muscle in mice and to stimulate the expression of clock genes, such as Bmall and Rev-erba, by coactivating the ROR family of orphan nuclear receptors. Pgc-l $\alpha$-deficient mice had abnormal diurnal rhythms of activity, body temperature and metabolic rate due to the abnormal expression of clock genes and of those involved in energy metabolism (Figure 1) [167].

The cyclic nucleotide adenosine 3',5'-monophosphate (cAMP) plays a central physiological role in the regulation of energy metabolism, being activated by glucagon and inhibited by insulin. It was shown that cAMP signalling plays also a part in the regulation of the oscillatory network, since its signalling was rhythmic and involved in keeping the transcriptional loop in the SCN, setting amplitude, phase, and period. Moreover, its role extended in peripheral mammalian tissues and cell lines as well, supporting the progression of transcriptional rhythms [168]. PARP-1 is an NAD ${ }^{+}$-dependent ADP-ribosyltransferase that controls cell progression and metabolic homeostasis. In the liver the activity of PARP-1 oscillated in a circadian manner and was regulated by feeding. PARP-1 was able to bind CLOCK at the beginning of the light phase and to poly(ADP-ribosyl)ate it. The absence of PARP-1 enhanced the binding of CLOCK -BMAL1 to DNA, leading to a shift of the interaction of CLOCK•BMAL1 with PER and CRY, resulting in the alteration of the CLOCK•BMAL1-dependent gene expression. PARP-1 is thus essential in food entrainment of peripheral circadian clocks and connects feeding with the circadian clock [169].

BMAL1 and CLOCK are also major factors in the regulation of glucose and triglyceride homeostasis, as gluconeogenesis was abolished by deletion of Bmall and depressed in Clock mutants, even if the response of glucagon and corticosterone to insulin-induced hypoglycaemia was retained. Additionally, a high-fat diet increased circadian variation in glucose tolerance and insulin sensitivity, and mutations of Clock were able to restore the chow-fed phenotype [170]. Circadian clock controlled also hepatic gluconeogenesis, which during fasting was initiated by the cAMP-mediated phosphorylation of cAMP response element-binding protein (CREB). CREB activity was modulated during fasting by Cryl and Cry2. Cryl expression was elevated during the night-day transition, when it reduced the expression of fasting gluconeogenic genes by blocking glucagon-mediated increases in intracellular cAMP concentrations and protein kinase A-mediated phosphorylation of CREB. As hepatic overexpression of Cryl lowered blood glucose concentrations and improved insulin sensitivity in insulin-resistant mice, molecules able to enhance cryptochrome activity might theoretically be useful to cope with type 2 diabetes [171].

The deep relationship between the circadian clock machinery and metabolism was further corroborated by the discovery that the highly metabolically-controlled transcription factor REV-ERB $\alpha$ was also of key importance in the synchronisation of the circadian clock, and synthetic REV-ERB $\alpha$ agonists were recently proposed as positive regulators of both metabolism and the circadian clock [172,173]. Other points of contacts between the circadian clock and metabolism, and in particular 
with the development of metabolic diseases were found, and for example, the activity of the stomach cells that secrete ghrelin was entrained by food through a clock-mediated mechanism [174].

\section{Conclusions}

Circadian rhythms are now recognised as an essential component of the complex physiological machinery that regulates the deep functioning of all organisms, from plants to mammals. The inseparable link between the circadian clock and energy metabolism has been unravelled in the last years, showing how the central clock is able to synchronise the clocks present in the peripheral organs. Up to now, many genes involved in the control of metabolism have been shown to be under circadian regulation, and hence any perturbation of this delicate equilibrium may result in the development of severe pathological conditions. However, several aspects are still under investigation, and possible new discoveries will be helpful not only to increase our scientific knowledge, but also to try to improve public health.

In fact, in the last years, a large part of the general population experienced an increased incidence of sleep reduction and/or a diminished quality of the sleep mainly due to shift work or frequent long transmeridian travels. This disruption of our circadian rhythms was correlated to an augmented incidence of metabolic and cardiovascular diseases (Figure 3) [175-181]. In this light, new public health policies trying to make larger parts of the population aware of the risks of a bad lifestyle, together with the possible future development of new drugs able to interact directly with the circadian molecular machinery might be beneficial in containing the new rising pandemic in metabolic pathologies.

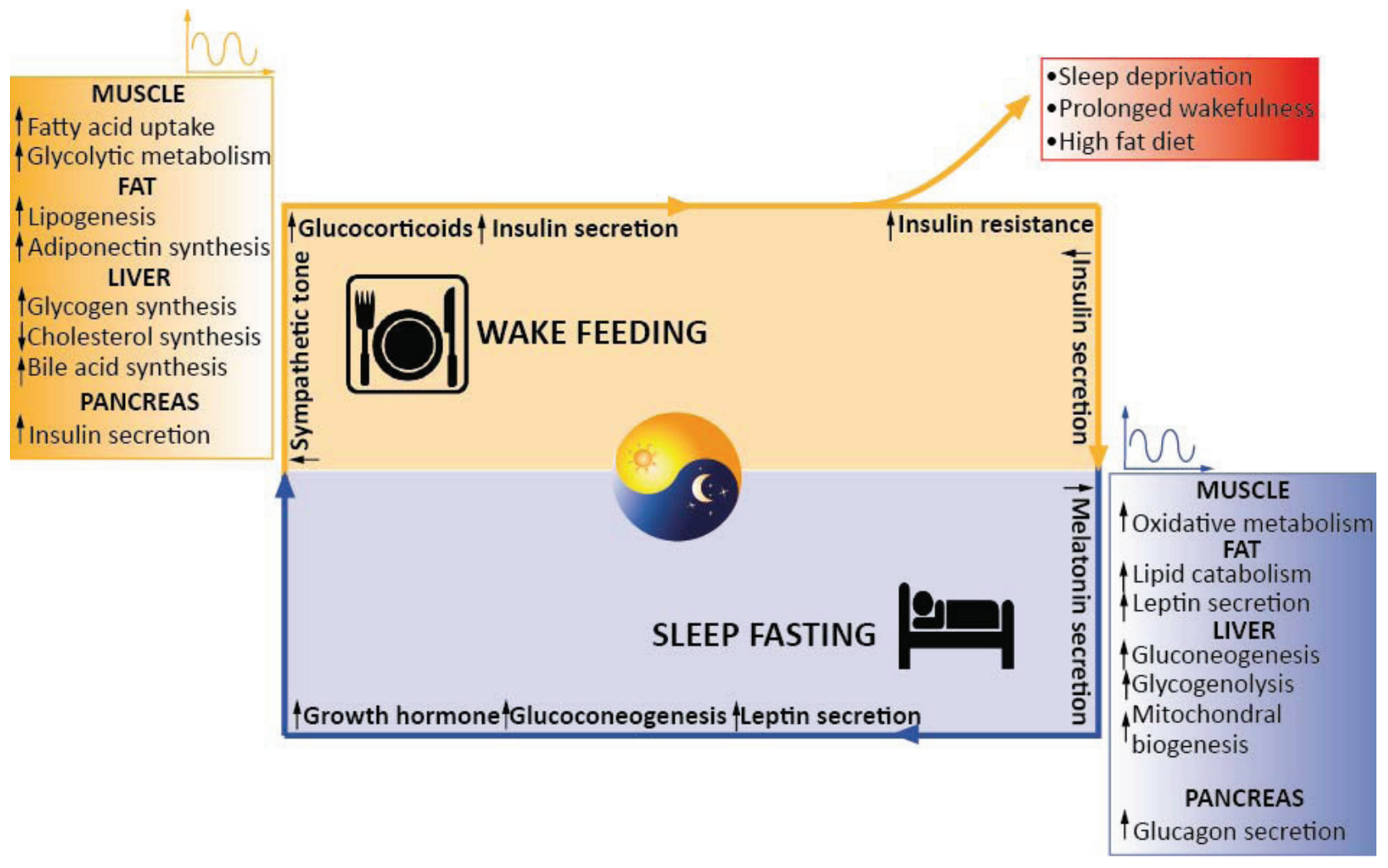

Figure 3. Schematic view of the tight association between circadian rhythms, metabolism and hormonal homeostasis in humans. Waves symbolises circadian regulation. See text for details. 


\section{Author Contributions}

Davide Gnocchi wrote the manuscript, Matteo Pedrelli realised the figures and revised the manuscript, and Eva Hurt-Camejo and Paolo Parini revised the manuscript.

\section{Conflicts of Interest}

The authors declare no conflict of interest.

\section{References}

1. Quehenberger, O.; Dennis, E.A. The human plasma lipidome. N. Engl. J. Med. 2011, 365, 18121823.

2. Foster, R.G.; Kreitzman, L. Rhythms of Life: The Biological Clocks that Control the Daily Lives of Every Living Thing; Yale University Press: New Haven, CT, USA, 2004.

3. De Mairan, J.-J.O. Observation Botanique. Avaliable online: https://www.bibnum.education.fr/ sciencesdelavie/biologie/observation-botanique (accessed on 20 January 2015).

4. De Candolle, M. De l'influence de la lumiere sur les végétaux. Physiol. Vég. 1832, 4, 1069.

5. Bünning, E. The Physiological Clock-Circadian Rhythms in Biological Chronometry; The English University Press Ltd.: London, UK, 1973.

6. Berson, D.M.; Dunn, F.A.; Takao, M. Phototransduction by retinal ganglion cells that set the circadian clock. Science 2002, 295, 1070-1073.

7. Richter, C. Sleep and activity: Their relation to the 24 hour clock. In Sleep and Altered States $o$ Consciousness; Williams \& Williams Company: Baltimore, MD, USA, 1967; pp. 8-29.

8. Stephan, F.K.; Zucker, I. Circadian rhythms in drinking behavior and locomotor activity of rats are eliminated by hypothalamic lesions. Proc. Natl. Acad. Sci. USA 1972, 69, 1583-1586.

9. Moore, R.Y.; Eichler, V.B. Loss of a circadian adrenal corticosterone rhythm following suprachiasmatic lesions in the rat. Brain Res. 1972, 42, 201-206.

10. Inouye, S.T.; Kawamura, H. Persistence of circadian rhythmicity in a mammalian hypothalamic "island" containing the suprachiasmatic nucleus. Proc. Natl. Acad. Sci. USA 1979, 76, 59625966.

11. Ralph, M.R.; Menaker, M. A mutation of the circadian system in golden hamsters. Science $\mathbf{1 9 8 8 \text { , }}$ 241, 1225-1227.

12. Ralph, M.R.; Foster, R.G.; Davis, F.C.; Menaker, M. Transplanted suprachiasmatic nucleus determines circadian period. Science 1990, 247, 975-978.

13. Konopka, R.J.; Benzer, S. Clock mutants of Drosophila melanogaster. Proc. Natl. Acad. Sci. USA 1971, 68, 2112-2116.

14. Siwicki, K.K.; Eastman, C.; Petersen, G.; Rosbash, M.; Hall, J.C. Antibodies to the period gene product of Drosophila reveal diverse tissue distribution and rhythmic changes in the visual system. Neuron 1988, 1, 141-150.

15. Hardin, P.E.; Hall, J.C.; Rosbash, M. Feedback of the Drosophila period gene product on circadian cycling of its messenger RNA levels. Nature 1990, 343, 536-540. 
16. Sehgal, A.; Rothenfluh-Hilfiker, A.; Hunter-Ensor, M.; Chen, Y.; Myers, M.P.; Young, M.W. Rhythmic expression of timeless: A basis for promoting circadian cycles in period gene autoregulation. Science 1995, 270, 808-810.

17. Vitaterna, M.H.; King, D.P.; Chang, A.M.; Kornhauser, J.M.; Lowrey, P.L.; McDonald, J.D.; Dove, W.F.; Pinto, L.H.; Turek, F.W.; Takahashi, J.S. Mutagenesis and mapping of a mouse gene, Clock, essential for circadian behavior. Science 1994, 264, 719-725.

18. Veleri, S.; Brandes, C.; Helfrich-Förster, C.; Hall, J.C.; Stanewsky, R. A self-sustaining, light-entrainable circadian oscillator in the Drosophila brain. Curr. Biol. 2003, 13, 1758-1767.

19. Tei, H.; Okamura, H.; Shigeyoshi, Y.; Fukuhara, C.; Ozawa, R.; Hirose, M.; Sakaki, Y. Circadian oscillation of a mammalian homologue of the Drosophila period gene. Nature 1997, 389, 512 516.

20. Shigeyoshi, Y.; Taguchi, K.; Yamamoto, S.; Takekida, S.; Yan, L.; Tei, H.; Moriya, T.; Shibata, S.; Loros, J.J.; Dunlap, J.C.; et al. Light-induced resetting of a mammalian circadian clock is associated with rapid induction of the mPer1 transcript. Cell 1997, 91, 1043-1053.

21. Zylka, M.J.; Shearman, L.P.; Weaver, D.R.; Reppert, S.M. Three period homologs in mammals: Differential light responses in the suprachiasmatic circadian clock and oscillating transcripts outside of brain. Neuron 1998, 20, 1103-1110.

22. Barnes, J.W.; Tischkau, S.A.; Barnes, J.A.; Mitchell, J.W.; Burgoon, P.W.; Hickok, J.R.; Gillette, M.U. Requirement of mammalian timeless for circadian rhythmicity. Science 2003, 302, 439442.

23. Li, Z.; Stuart, R.O.; Qiao, J.; Pavlova, A.; Bush, K.T.; Pohl, M.; Sakurai, H.; Nigam, S.K. A role for Timeless in epithelial morphogenesis during kidney development. Proc. Natl. Acad. Sci. USA 2000, 97, 10038-10043.

24. O'Reilly. L.P.; Watkins, S.C.; Smithgall, T.E. An unexpected role for the clock protein timeless in developmental apoptosis. PLOS ONE 2011, 6, e17157.

25. Gekakis, N.; Staknis, D.; Nguyen, H.B.; Davis, F.C.; Wilsbacher, L.D.; King, D.P.; Takahashi, J.S.; Weitz, C.J. Role of the CLOCK protein in the mammalian circadian mechanism. Science 1998, 280, 1564-1569.

26. Thresher, R.J.; Vitaterna, M.H.; Miyamoto, Y.; Kazantsev, A.; Hsu, D.S.; Petit, C.; Selby, C.P.; Dawut, L.; Smithies, O.; Takahashi, J.S.; et al. Role of mouse cryptochrome blue-light photoreceptor in circadian photoresponses. Science 1998, 282, 1490-1494.

27. Vitaterna, M.; Selby, C.P.; Todo, T.; Niwa, H.; Thompson, C.; Fruechte, E.M.; Hitomi, K.; Thresher, R.J.; Ishikawa, T.; Miyazaki, J.; et al. Differential regulation of mammalian period genes and circadian rhythmicity by cryptochromes 1 and 2. Proc. Natl. Acad. Sci. USA 1999, 96, 12114 12119.

28. Van der Horst, G.T.; Muijtjens, M.; Kobayashi, K.; Takano, R.; Kanno, S.; Takao, M.; de Wit, J.; Verkerk, A.; Eker, A.P.; van Leenen, D.; et al. Mammalian Cry1 and Cry2 are essential for maintenance of circadian rhythms. Nature 1999, 398, 627-630.

29. Preitner, N.; Damiola, F.; Lopez-Molina, L.; Zakany, J.; Duboule, D.; Albrecht, U.; Schibler, U. The orphan nuclear receptor REV-ERBalpha controls circadian transcription within the positive limb of the mammalian circadian oscillator. Cell 2002, 110, 251-260. 
30. Sato, T.K.; Panda, S.; Miraglia, L.J.; Reyes, T.M.; Rudic, R.D.; McNamara, P.; Naik, K.A.; FitzGerald, G.A.; Kay, S.A.; Hogenesch, J.B. A functional genomics strategy reveals Rora as a component of the mammalian circadian clock. Neuron 2004, 43, 527-537.

31. Guillaumond, F.; Dardente, H.; Giguère, V.; Cermakian, N. Differential control of Bmal1 circadian transcription by REV-ERB and ROR nuclear receptors. J. Biol. Rhythms 2005, 20, 391-403.

32. Liu, A.C.; Tran, H.G.; Zhang, E.E.; Priest, A.A.; Welsh, D.K.; Kay, S.A. Redundant function of REV-ERBalpha and beta and non-essential role for Bmall cycling in transcriptional regulation of intracellular circadian rhythms. PLOS Genet. 2008, 4, e1000023.

33. Cho, H.; Zhao, X.; Hatori, M.; Yu, R.T.; Barish, G.D.; Lam, M.T.; Chong, L.W.; DiTacchio, L.; Atkins, A.R.; Glass, C.K.; et al. Regulation of circadian behaviour and metabolism by REV-ERB- $\alpha$ and REV-ERB- $\beta$. Nature 2012, 485, 123-127.

34. Lowrey, P.L.; Shimomura, K.; Antoch, M.P.; Yamazaki, S.; Zemenides, P.D.; Ralph, M.R.; Menaker, M.; Takahashi, J.S. Positional syntenic cloning and functional characterization of the mammalian circadian mutation tau. Science 2000, 288, 483-492.

35. Camacho, F.; Cilio, M.; Guo, Y.; Virshup, D.M.; Patel, K.; Khorkova, O.; Styren, S.; Morse, B.; Yao, Z.; Keesler, G.A. Human casein kinase Idelta phosphorylation of human circadian clock proteins period 1 and 2. FEBS Lett. 2001, 489, 159-165.

36. Eide, E.J.; Woolf, M.F.; Kang, H.; Woolf, P.; Hurst, W.; Camacho, F.; Vielhaber, E.L.; Giovanni, A.; Virshup, D.M. Control of mammalian circadian rhythm by CKIepsilon-regulated proteasome-mediated PER2 degradation. Mol. Cell. Biol. 2005, 25, 2795-2807.

37. Provencio, I.; Rodriguez, I.R.; Jiang, G.; Hayes, W.P.; Moreira, E.F.; Rollag, M.D. A novel human opsin in the inner retina. J. Neurosci. 2000, 20, 600-605.

38. Hattar, S.; Liao, H.W.; Takao, M.; Berson, D.M.; Yau, K.W. Melanopsin-containing retinal ganglion cells: Architecture, projections, and intrinsic photosensitivity. Science 2002, 295, 1065-1070.

39. Hattar, S.; Lucas, R.J.; Mrosovsky, N.; Thompson, S.; Douglas, R.H.; Hankins, M.W.; Lem, J.; Biel, M.; Hofmann, F.; Foster, R.G.; et al. Melanopsin and rod-cone photoreceptive systems account for all major accessory visual functions in mice. Nature 2003, 424, 76-81.

40. Doi, M.; Hirayama, J.; Sassone-Corsi, P. Circadian regulator CLOCK is a histone acetyltransferase. Cell 2006, 125, 497-508.

41. Hirayama, J.; Sahar, S.; Grimaldi, B.; Tamaru, T.; Takamatsu, K.; Nakahata, Y.; Sassone-Corsi, P. CLOCK-mediated acetylation of BMAL1 controls circadian function. Nature 2007, 450, 1086-1090.

42. Schwartz, M.D.; Urbanski, H.F.; Nunez, A.A.; Smale, L. Projections of the suprachiasmatic nucleus and ventral subparaventricular zone in the Nile grass rat (Arvicanthis niloticus). Brain Res. 2011, 1367, 146-161.

43. Leak, R.K.; Card, J.P.; Moore, R.Y. Suprachiasmatic pacemaker organization analyzed by viral transynaptic transport. Brain Res. 1999, 819, 23-32.

44. Hermes, M.L.; Coderre, E.M.; Buijs, R.M.; Renaud, L.P. GABA and glutamate mediate rapid neurotransmission from suprachiasmatic nucleus to hypothalamic paraventricular nucleus in rat. J. Physiol. 1996, 496, 749-757. 
45. Kalsbeek, A.; Buijs, R.M.; van Heerikhuize, J.J.; Arts, M.; van der Woude, T.P. Vasopressin-containing neurons of the suprachiasmatic nuclei inhibit corticosterone release. Brain Res. 1992, 580, 62-67.

46. Kalsbeek, A.; Buijs, R.M. Peptidergic transmitters of the suprachiasmatic nuclei and the control of circadian rhythmicity. Prog. Brain Res. 1992, 92, 321-333.

47. Kraves, S.; Weitz, C.J. A role for cardiotrophin-like cytokine in the circadian control of mammalian locomotor activity. Nat. Neurosci. 2006, 9, 212-219.

48. Cheng, M.Y.; Bullock, C.M.; Li, C.; Lee, A.G.; Bermak, J.C.; Belluzzi, J.; Weaver, D.R.; Leslie, F.M.; Zhou, Q.Y. Prokineticin 2 transmits the behavioural circadian rhythm of the suprachiasmatic nucleus. Nature 2002, 417, 405-410.

49. Kramer, A.; Yang, F.C.; Snodgrass, P.; Li, X.; Scammell, T.E.; Davis, F.C.; Weitz, C.J. Regulation of daily locomotor activity and sleep by hypothalamic EGF receptor signaling. Science 2001, 294, 2511-2515.

50. Li, X.; Sankrithi, N.; Davis, F.C. Transforming growth factor-alpha is expressed in astrocytes of the suprachiasmatic nucleus in hamster: Role of glial cells in circadian clocks. Neuroreport 2002 , $13,2143-2147$.

51. Zimmerman, N.H.; Menaker, M. The pineal gland: A pacemaker within the circadian system of the house sparrow. Proc. Natl. Acad. Sci. USA 1979, 76, 999-1003.

52. Reppert, S.M. Melatonin receptors: Molecular biology of a new family of G protein-coupled receptors. J. Biol. Rhythms 1997, 12, 528-531.

53. Scheer, F.A.; van Montfrans, G.A.; van Someren, E.J.; Mairuhu, G.; Buijs, R.M. Daily nighttime melatonin reduces blood pressure in male patients with essential hypertension. Hypertension 2004, 43, 192-197.

54. Pandi-Perumal, S.R.; Srinivasan, V.; Maestroni, G.J.; Cardinali, D.P.; Poeggeler, B.; Hardeland, R. Melatonin: Nature's most versatile biological signal? FEBS J. 2006, 273, 2813-2838.

55. Schwartz, W.J.; Reppert, S.M. Neural regulation of the circadian vasopressin rhythm in cerebrospinal fluid: A pre-eminent role for the suprachiasmatic nuclei. J. Neurosci. 1985, 5, 2771-2778.

56. Kalsbeek, A.; Buijs, R.M.; Engelmann, M.; Wotjak, C.T.; Landgraf, R. In vivo measurement of a diurnal variation in vasopressin release in the rat suprachiasmatic nucleus. Brain Res. 1995, 682, 75-82.

57. Kametani, H.; Kawamura, H. Circadian rhythm of cortical acetylcholine release as measured by in vivo microdialysis in freely moving rats. Neurosci. Lett. 1991, 132, 263-266.

58. Liu, C.; Gillette, M.U. Cholinergic regulation of the suprachiasmatic nucleus circadian rhythm via a muscarinic mechanism at night. J. Neurosci. 1996, 16, 744-751.

59. Buijs, R.M.; Wortel, J.; van Heerikhuize, J.J.; Feenstra, M.G.; Ter Horst, G.J.; Romijn, H.J.; Kalsbeek, A. Anatomical and functional demonstration of a multisynaptic suprachiasmatic nucleus adrenal (cortex) pathway. Eur. J. Neurosci. 1999, 11, 1535-1544.

60. Oster, H.; Damerow, S.; Kiessling, S.; Jakubcakova, V.; Abraham, D.; Tian, J.; Hoffmann, M.W.; Eichele, G. The circadian rhythm of glucocorticoids is regulated by a gating mechanism residing in the adrenal cortical clock. Cell Metab. 2006, 4, 163-173. 
61. Reddy, A.B.; Maywood, E.S.; Karp, N.A.; King, V.M.; Inoue, Y.; Gonzalez, F.J.; Lilley, K.S.; Kyriacou, C.P.; Hastings, M.H. Glucocorticoid signaling synchronizes the liver circadian transcriptome. Hepatology 2007, 45, 1478-1488.

62. Balsalobre, A.; Brown, S.A.; Marcacci, L.; Tronche, F.; Kellendonk, C.; Reichardt, H.M.; Schütz, G.; Schibler, U. Resetting of circadian time in peripheral tissues by glucocorticoid signaling. Science 2000, 289, 2344-2347.

63. Yamazaki, S.; Numano, R.; Abe, M.; Hida, A.; Takahashi, R.; Ueda, M.; Block, G.D.; Sakaki, Y.; Menaker, M.; Tei, H. Resetting central and peripheral circadian oscillators in transgenic rats. Science 2000, 288, 682-685.

64. Yoo, S.H.; Yamazaki, S.; Lowrey, P.L.; Shimomura, K.; Ko, C.H.; Buhr, E.D.; Siepka, S.M.; Hong, H.K.; Oh, W.J.; Yoo, O.J.; et al. PERIOD2::LUCIFERASE real-time reporting of circadian dynamics reveals persistent circadian oscillations in mouse peripheral tissues. Proc. Natl. Acad. Sci. USA 2004, 101, 5339-5446.

65. Balsalobre, A.; Damiola, F.; Schibler, U. A serum shock induces circadian gene expression in mammalian tissue culture cells. Cell 1998, 93, 929-937.

66. Yagita, K.; Tamanini, F.; van der Horst, G.T.; Okamura, H. Molecular mechanisms of the biological clock in cultured fibroblasts. Science 2001, 292, 278-281.

67. Nagoshi, E.; Saini, C.; Bauer, C.; Laroche, T.; Naef, F.; Schibler, U. Circadian gene expression in individual fibroblasts: Cell-autonomous and self-sustained oscillators pass time to daughter cells. Cell 2004, 119, 693-705.

68. Brown, S.A.; Fleury-Olela, F.; Nagoshi, E.; Hauser, C.; Juge, C.; Meier, C.A.; Chicheportiche, R.; Dayer, J.M.; Albrecht, U.; Schibler, U. The period length of fibroblast circadian gene expression varies widely among human individuals. PLOS Biol. 2005, 3, e338.

69. Yamamoto, T.; Nakahata, Y.; Soma, H.; Akashi, M.; Mamine, T.; Takumi, T. Transcriptional oscillation of canonical clock genes in mouse peripheral tissues. BMC Mol. Biol. 2004, 5, 18.

70. Granados-Fuentes, D.; Saxena, M.T.; Prolo, L.M.; Aton, S.J.; Herzog, E.D. Olfactory bulb neurons express functional, entrainable circadian rhythms. Eur. J. Neurosci. 2004, 19, 898-906.

71. Granados-Fuentes, D.; Prolo, L.M.; Abraham, U.; Herzog, E.D. The suprachiasmatic nucleus entrains, but does not sustain, circadian rhythmicity in the olfactory bulb. J. Neurosci. 2004, 24, 615-619.

72. Granados-Fuentes, D.; Tseng, A.; Herzog, E.D. A circadian clock in the olfactory bulb controls olfactory responsivity. J. Neurosci. 2006, 26, 12219-12225.

73. Panda, S.; Antoch, M.P.; Miller, B.H.; Su, A.I.; Schook, A.B.; Straume, M.; Schultz, P.G.; Kay, S.A.; Takahashi, J.S.; Hogenesch, J.B. Coordinated transcription of key pathways in the mouse by the circadian clock. Cell 2002, 109, 307-320.

74. Storch, K.F.; Lipan, O.; Leykin, I.; Viswanathan, N.; Davis, F.C.; Wong, W.H.; Weitz, C.J. Extensive and divergent circadian gene expression in liver and heart. Nature 2002, 417, 78-83.

75. Miller, B.H.; McDearmon, E.L.; Panda, S.; Hayes, K.R.; Zhang, J.; Andrews, J.L.; Antoch, M.P.; Walker, J.R.; Esser, K.A.; Hogenesch, J.B.; et al. Circadian and CLOCK-controlled regulation of the mouse transcriptome and cell proliferation. Proc. Natl. Acad. Sci. USA 2007, 104, 33423347. 
76. Storch, K.F.; Paz, C.; Signorovitch, J.; Raviola, E.; Pawlyk, B.; Li, T.; Weitz, C.J. Intrinsic circadian clock of the mammalian retina: Importance for retinal processing of visual information. Cell 2007, 130, 730-741.

77. Yan, J.; Wang, H.; Liu, Y.; Shao, C. Analysis of gene regulatory networks in the mammalian circadian rhythm. PLOS Comput. Biol. 2008, 4, e1000193.

78. Ishida, A.; Mutoh, T.; Ueyama, T.; Bando, H.; Masubuchi, S.; Nakahara, D.; Tsujimoto, G.; Okamura, H. Light activates the adrenal gland: Timing of gene expression and glucocorticoid release. Cell Metab. 2005, 2, 297-307.

79. Kalsbeek, A.; Foppen, E.; Schalij, I.; van Heijningen, C.; van der Vliet, J.; Fliers, E.; Buijs, R.M. Circadian control of the daily plasma glucose rhythm: An interplay of GABA and glutamate. PLOS ONE 2008, 3, e3194.

80. Cailotto, C.; Lei, J.; van der Vliet, J.; van Heijningen, C.; van Eden, C.G.; Kalsbeek, A.; Pévet, P.; Buijs, R.M. Effects of nocturnal light on (clock) gene expression in peripheral organs: A role for the autonomic innervation of the liver. PLOS ONE 2009, 4, e5650.

81. Akhtar, R.A.; Reddy, A.B.; Maywood, E.S.; Clayton, J.D.; King, V.M.; Smith, A.G.; Gant, T.W.; Hastings, M.H.; Kyriacou, C.P. Circadian cycling of the mouse liver transcriptome, as revealed by cDNA microarray, is driven by the suprachiasmatic nucleus. Curr. Biol. 2002, 12, 540-550.

82. Kornmann, B.; Schaad, O.; Bujard, H.; Takahashi, J.S.; Schibler, U. System-driven and oscillator-dependent circadian transcription in mice with a conditionally active liver clock. PLOS Biol. 2007, 5, e34.

83. Stokkan, K.A.; Yamazaki, S.; Tei, H.; Sakaki, Y.; Menaker, M. Entrainment of the circadian clock in the liver by feeding. Science 2001, 291, 490-493.

84. Guo, H.; Brewer, J.M.; Champhekar, A.; Harris, R.B.; Bittman, E.L. Differential control of peripheral circadian rhythms by suprachiasmatic-dependent neural signals. Proc. Natl. Acad. Sci. USA 2005, 102, 3111-3116.

85. Vollmers, C.; Gill, S.; DiTacchio, L.; Pulivarthy, S.R.; Le, H.D.; Panda, S. Time of feeding and the intrinsic circadian clock drive rhythms in hepatic gene expression. Proc. Natl. Acad. Sci. USA 2009, 106, 21453-21458.

86. Strader, A.D.; Woods, S.C. Gastrointestinal hormones and food intake. Gastroenterology 2005, 128, 175-191.

87. Pittendrigh, C.S. On temperature independence in the clock system controlling emergence time in Drosophila. Proc. Natl. Acad. Sci. USA 1954, 40, 1018-1029.

88. Konopka, R.J.; Pittendrigh, C.; Orr, D. Reciprocal behaviour associated with altered homeostasis and photosensitivity of Drosophila clock mutants. J. Neurogenet. 1989, 6, 1-10.

89. Buhr, E.D.; Yoo, S.H.; Takahashi, J.S. Temperature as a universal resetting cue for mammalian circadian oscillators. Science 2010, 330, 379-385.

90. Kaushik, R.; Nawathean, P.; Busza, A.; Murad, A.; Emery, P.; Rosbash, M. PER-TIM interactions with the photoreceptor cryptochrome mediate circadian temperature responses in Drosophila. PLOS Biol. 2007, 5, e146.

91. Dibner, C.; Sage, D.; Unser, M.; Bauer, C.; D’Eysmond, T.; Naef, F.; Schibler, U. Circadian gene expression is resilient to large fluctuations in overall transcription rates. EMBO J. 2009, 28, $123-134$. 
92. Eastman, C.I.; Mistlberger, R.E.; Rechtschaffen, A. Suprachiasmatic nuclei lesions eliminate circadian temperature and sleep rhythms in the rat. Physiol. Behav. 1984, 32, 357-368.

93. Gachon, F.; Olela, F.F.; Schaad, O.; Descombes, P.; Schibler, U. The circadian PAR-domain basic leucine zipper transcription factors DBP, TEF, and HLF modulate basal and inducible xenobiotic detoxification. Cell Metab. 2006, 4, 25-36.

94. Lamia, K.A.; Storch, K.F.; Weitz, C.J. Physiological significance of a peripheral tissue circadian clock. Proc. Natl. Acad. Sci. USA 2008, 105, 15172-15177.

95. Englund, A.; Kovanen, L.; Saarikoski, S.T.; Haukka, J.; Reunanen, A.; Aromaa, A.; Lönnqvist, J.; Partonen, T. NPAS2 and PER2 are linked to risk factors of the metabolic syndrome. $J$. Circadian Rhythms 2009, 7, 5.

96. Le Martelot, G.; Claudel, T.; Gatfield, D.; Schaad, O.; Kornmann, B.; Lo Sasso, G.; Moschetta, A.; Schibler, U. REV-ERBalpha participates in circadian SREBP signaling and bile acid homeostasis. PLOS Biol. 2009, 7, e1000181.

97. Ramsey, K.M.; Yoshino, J.; Brace, C.S.; Abrassart, D.; Kobayashi, Y.; Marcheva, B.; Hong, H.K.; Chong, J.L.; Buhr, E.D.; Lee, C.; et al. Circadian clock feedback cycle through NAMPTmediated NAD+ biosynthesis. Science 2009, 324, 651-654.

98. Sadacca, L.A.; Lamia, K.A.; deLemos, A.S.; Blum, B.; Weitz, C.J. An intrinsic circadian clock of the pancreas is required for normal insulin release and glucose homeostasis in mice. Diabetologia 2011, 54, 120-124.

99. Marcheva, B.; Ramsey, K.M.; Buhr, E.D.; Kobayashi, Y.; Su, H.; Ko, C.H.; Ivanova, G.; Omura, C.; Mo, S.; Vitaterna, M.H.; et al. Disruption of the clock components CLOCK and BMAL1 leads to hypoinsulinaemia and diabetes. Nature 2010, 466, 627-631.

100. Schlierf, G.; Dorow, E. Diurnal patterns of triglycerides, free fatty acids, blood sugar, and insulin during carbohydrate-induction in man and their modification by nocturnal suppression of lipolysis. J. Clin. Invest. 1973, 52, 732-740.

101. Fukagawa, K.; Gou, H.M.; Wolf, R.; Tso, P. Circadian rhythm of serum and lymph apolipoprotein AIV in ad libitum-fed and fasted rats. Am. J. Physiol. 1994, 267, R1385-R1390.

102. Morgan, L.; Arendt, J.; Owens, D.; Folkard, S.; Hampton, S.; Deacon, S.; English, J.; Ribeiro, D.; Taylor, K. Effects of the endogenous clock and sleep time on melatonin, insulin, glucose and lipid metabolism. J. Endocrinol. 1998, 157, 443-451.

103. Dallmann, R.; Viola, A.U.; Tarokh, L.; Cajochen, C.; Brown S.A. The human circadian metabolome. Proc. Natl. Acad. Sci. USA 2012, 109, 2625-2629.

104. Chua, E.C.; Shui, G.; Lee, I.T.; Lau, P.; Tan, L.C.; Yeo, S.C.; Lam, B.D.; Bulchand, S.; Summers, S.A.; Puvanendran, K.; et al. Extensive diversity in circadian regulation of plasma lipids and evidence for different circadian metabolic phenotypes in humans. Proc. Natl. Acad. Sci. USA 2013, 110, 14468-14473.

105. Turek, F.W.; Joshu, C.; Kohsaka, A.; Lin, E.; Ivanova, G.; McDearmon, E.; Laposky, A.; Losee-Olson, S.; Easton, A.; Jensen, D.R.; et al. Obesity and metabolic syndrome in circadian Clock mutant mice. Science 2005, 308, 1043-1045.

106. Baggs, J.E.; Price, T.S.; DiTacchio, L.; Panda, S.; Fitzgerald, G.A.; Hogenesch, J.B. Network features of the mammalian circadian clock. PLOS Biol. 2009, 7, e52. 
107. Green, C.B.; Douris, N.; Kojima, S.; Strayer, C.A.; Fogerty, J.; Lourim, D.; Keller, S.R.; Besharse, J.C. Loss of Nocturnin, a circadian deadenylase, confers resistance to hepatic steatosis and diet-induced obesity. Proc. Natl. Acad. Sci. USA 2007, 104, 9888-9893.

108. Kudo, T.; Tamagawa, T.; Kawashima, M.; Mito, N.; Shibata, S. Attenuating effect of clock mutation on triglyceride contents in the ICR mouse liver under a high-fat diet. J. Biol. Rhythms 2007, 22, 312-323.

109. Hoogerwerf, W.A. Biologic clocks and the gut. Curr. Gastroenterol. Rep. 2006, 8, 353-359.

110. Soták, M.; Polidarová, L.; Musílková, J.; Hock, M.; Sumová, A.; Pácha, J. Circadian regulation of electrolyte absorption in the rat colon. Am. J. Physiol. Gastrointest. Liver Physiol. 2011, 301, G1066-G1074.

111. Hoogerwerf, W.A.; Hellmich, H.L.; Cornélissen, G.; Halberg, F.; Shahinian, V.B.; Bostwick, J.; Savidge, T.C.; Cassone, V.M. Clock gene expression in the murine gastrointestinal tract: Endogenous rhythmicity and effects of a feeding regimen. Gastroenterology 2007, 133, 1250 1260.

112. Pan, X.; Hussain, M.M. Clock is important for food and circadian regulation of macronutrient absorption in mice. J. Lipid. Res. 2009, 50, 1800-1813.

113. Hoogerwerf, W.A.; Shahinian, V.B.; Cornélissen, G.; Halberg, F.; Bostwick, J.; Timm, J.; Bartell, P.A.; Cassone, V.M. Rhythmic changes in colonic motility are regulated by period genes. Am. J. Physiol. Gastrointest. Liver Physiol. 2010, 298, G143-G150.

114. Sládek, M.; Rybová, M.; Jindráková, Z.; Zemanová, Z.; Polidarová, L.; Mrnka, L.; O’Neill, J.; Pácha, J.; Sumová, A. Insight into the circadian clock within rat colonic epithelial cells. Gastroenterology 2007, 133, 1240-1249.

115. Hoogerwerf, G.A. Role of clock genes in gastrointestinal motility. Am. J. Physiol. Gastrointest. Liver Physiol. 2010, 299, G549-G555.

116. Konturek, P.C.; Brzozowski, T.; Konturek, S.J. Gut clock: Implication of circadian rhythms in the gastrointestinal tract. J. Physiol. Pharmacol. 2011, 62, 139-150.

117. Phan, C.T.; Tso, P. Intestinal lipid absorption and transport. Front. Biosci. 2001, 6, D299-D319.

118. Mu, H.; Нøy, C.E. The digestion of dietary triacylglycerols. Prog. Lipid Res. 2004, 43, 105-133.

119. Abumrad, N.A.; Davidson, N.O. Role of the gut in lipid homeostasis. Physiol. Rev. 2012, 92, 1061-1085.

120. Hussain, M.M.; Kancha, R.K.; Zhou, Z.; Luchoomun, J.; Zu, H.; Bakillah, A. Chylomicron assembly and catabolism: Role of apolipoproteins and receptors. Biochim. Biophys. Acta 1996, 1300, 151-170.

121. Hussain, M.M.; Rava, P.; Walsh, M.; Rana, M.; Iqbal, J. Multiple functions of microsomal triglyceride transfer protein. Nutr. Metab. (Lond.) 2012, 9, 14.

122. Hussain, M.M. A proposed model for the assembly of chylomicrons. Atherosclerosis 2000, 148, $1-15$.

123. Luchoomun, J.; Hussain, M.M. Assembly and secretion of chylomicrons by differentiated Caco-2 cells. Nascent triglycerides and preformed phospholipids are preferentially used for lipoprotein assembly. J. Biol. Chem. 1999, 274, 19565-19572.

124. Iqbal, J.; Anwar, K.; Hussain, M.M. Multiple, independently regulated pathways of cholesterol transport across the intestinal epithelial cells. J. Biol. Chem. 2003, 278, 31610-31620. 
125. Williams, K.J. Molecular processes that handle-And mishandle-Dietary lipids. J. Clin. Invest. 2008, 118, 3247-3259.

126. Brunham, L.R.; Kruit, J.K.; Iqbal, J.; Fievet, C.; Timmins, J.M.; Pape, T.D.; Coburn, B.A.; Bissada, N.; Staels, B.; Groen, A.K.; et al. Intestinal ABCA1 directly contributes to HDL biogenesis in vivo. J. Clin. Invest. 2006, 116, 1052-1062.

127. Pan, X.; Hussain, M.M. Diurnal regulation of microsomal triglyceride transfer protein and plasma lipid levels. J. Biol. Chem. 2007, 282, 24707-24719.

128. Pan, X.; Zhang, Y.; Wang, L.; Hussain, M.M. Diurnal regulation of MTP and plasma triglyceride by CLOCK is mediated by SHP. Cell Metab. 2010, 12, 174-186.

129. Pan, X.; Jiang, X.C.; Hussain, M.M. Impaired cholesterol metabolism and enhanced atherosclerosis in clock mutant mice. Circulation 2013, 28, 1758-1769.

130. Campos, H.; Khoo, C.; Sacks, F.M. Diurnal and acute patterns of postprandial apolipoprotein B-48 in VLDL, IDL, and LDL from normolipidemic humans. Atherosclerosis 2005, 181, 345351.

131. Back, P.; Hamprecht, B.; Lynen, F. Regulation of cholesterol biosynthesis in rat liver: Diurnal changes of activity and influence of bile acids. Arch. Biochem. Biophys. 1969, 133, 11-21.

132. Hamprecht, B.; Nüssler, C.; Lynen, F. Rhythmic changes of hydroxymethylglutaryl coenzyme a reductase activity in livers of fed and fasted rats. FEBS Lett. 1969, 4, 117-121.

133. Shapiro, D.J.; Rodwell, V.W. Diurnal variation and cholesterol regulation of hepatic HMG-CoA reductase activity. Biochem. Biophys. Res. Commun. 1969, 37, 867-872.

134. Edwards, P.A.; Muroya, H.; Gould, R.G. In vivo demonstration of the circadian rhythm of cholesterol biosynthesis in the liver and intestine of the rat. J. Lipid. Res. 1972, 13, 396-401.

135. Ho, K.J. Effect of cholesterol feeding on circadian rhythm of hepatic and intestinal cholesterol biosynthesis in hamsters. Proc. Soc. Exp. Biol. Med. 1975, 150, 271-277.

136. Mayer, D. The circadian rhythm of synthesis and catabolism of cholesterol. Arch. Toxicol. 1976, $36,267-276$.

137. Ho, K.J. Circadian rhythm of cholesterol biosynthesis: Dietary regulation in the liver and small intestine of hamsters. Int. J. Chronobiol. 1979, 6, 39-50.

138. Mortimer, B.C.; Beveridge, D.J.; Phan, C.T.; Lutton, C.; Redgrave, T.G. The diurnal rhythms of cholesterol metabolism and plasma clearance of model chylomicrons: Comparison of normal and genetically hypercholesterolemic rats (RICO). Comp. Biochem. Physiol. A Mol. Integr. Physiol. 1998, 120, 671-680.

139. Oishi, K.; Miyazaki, K.; Kadota, K.; Kikuno, R.; Nagase, T.; Atsumi, G.; Ohkura, N.; Azama, T.; Mesaki, M.; Yukimasa, S.; et al. Genome-wide expression analysis of mouse liver reveals CLOCK-regulated circadian output genes. J. Biol. Chem. 2003, 278, 41519-41527.

140. Jurevics, H.; Hostettler, J.; Barrett, C.; Morell, P.; Toews, A.D. Diurnal and dietary-induced changes in cholesterol synthesis correlate with levels of mRNA for HMG-CoA reductase. J. Lipid. Res. 2000, 41, 1048-1054.

141. Gälman, C.; Angelin, B.; Rudling, M. Bile acid synthesis in humans has a rapid diurnal variation that is asynchronous with cholesterol synthesis. Gastroenterology 2005, 129, 1445-1453.

142. Ho, K.J. Circadian distribution of bile acids in the enterohepatic circulatory system in rats. Am. J. Physiol. 1976, 230, 1331-1335. 
143. Ho, K.J. Circadian distribution of bile acid in the enterohepatic circulatory system in hamsters. J. Lipid. Res. 1976, 17, 600-604.

144. Mirani-Oostdijk, C.P.; Havekes, L.; van Gent, C.M.; Frölich, M.; Jansen, H.; Terpstra, J. Diurnal changes in serum triglycerides as related to changes in lipolytic enzymes, lipoproteins and hormones in patients with primary endogenous hypertriglyceridaemia on a carbohydrate-rich diet. Atherosclerosis 1985, 57, 129-137.

145. Zhang, Y.K.; Guo, G.L.; Klaassen, C.D. Diurnal variations of mouse plasma and hepatic bile acid concentrations as well as expression of biosynthetic enzymes and transporters. PLOS ONE 2011, 6, e16683.

146. Kohsaka, A.; Laposky, A.D.; Ramsey, K.M.; Estrada, C.; Joshu, C.; Kobayashi, Y.; Turek, F.W.; Bass, J. High-fat diet disrupts behavioral and molecular circadian rhythms in mice. Cell Metab. 2007, 6, 414-421.

147. Kudo, T.; Kawashima, M.; Tamagawa, T.; Shibata, S. Clock mutation facilitates accumulation of cholesterol in the liver of mice fed a cholesterol and/or cholic acid diet. Am. J. Physiol. Endocrinol. Metab. 2008, 294, E120-E130.

148. Oishi, K.; Atsumi, G.; Sugiyama, S.; Kodomari, I.; Kasamatsu, M.; Machida, K.; Ishida, N. Disrupted fat absorption attenuates obesity induced by a high-fat diet in Clock mutant mice. FEBS Lett. 2006, 580, 127-130.

149. Yanagihara, H.; Ando, H.; Hayashi, Y.; Obi, Y.; Fujimura, A. High-fat feeding exerts minimal effects on rhythmic mRNA expression of clock genes in mouse peripheral tissues. Chronobiol. Int. 2006, 23, 905-914.

150. Shimba, S.; Ishii, N.; Ohta, Y.; Ohno, T.; Watabe, Y.; Hayashi, M.; Wada, T.; Aoyagi, T.; Tezuka, M. Brain and muscle Arnt-like protein-1 (BMAL1), a component of the molecular clock, regulates adipogenesis. Proc. Natl. Acad. Sci. USA 2005, 102, 12071-12076.

151. Ishihara, A.; Matsumoto, E.; Horikawa, K.; Kudo, T.; Sakao, E.; Nemoto, A.; Iwase, K.; Sugiyama, H.; Tamura, Y.; Shibata, S.; et al. Multifactorial regulation of daily rhythms in expression of the metabolically responsive gene spot14 in the mouse liver. J. Biol. Rhythms. 2007, $22,324-334$.

152. Sonoda, J.; Mehl, I.R.; Chong, L.W.; Nofsinger, R.R.; Evans R.M. PGC-1beta controls mitochondrial metabolism to modulate circadian activity, adaptive thermogenesis, and hepatic steatosis. Proc. Natl. Acad. Sci. USA 2007, 104, 5223-5228.

153. Duez, H.; van der Veen, J.N.; Duhem, C.; Pourcet, B.; Touvier, T.; Fontaine, C.; Derudas, B.; Baugé, E.; Havinga, R.; Bloks, V.W.; et al. Regulation of bile acid synthesis by the nuclear receptor Rev-erbalpha. Gastroenterology 2008, 135, 689-698.

154. Grimaldi, B.; Bellet, M.M.; Katada, S.; Astarita, G.; Hirayama, J.; Amin, R.H.; Granneman, J.G.; Piomelli, D.; Leff, T.; Sassone-Corsi, P. PER2 controls lipid metabolism by direct regulation of PPAR $\gamma$. Cell Metab. 2010, 12, 509-520.

155. Adamovich, Y.; Rousso-Noori, L.; Zwighaft, Z.; Neufeld-Cohen, A.; Golik, M.; Kraut-Cohen, J.; Wang, M.; Han, X.; Asher, G. Circadian clocks and feeding time regulate the oscillations and levels of hepatic triglycerides. Cell Metab. 2014, 19, 319-330. 
156. Hughes, M.E.; DiTacchio, L.; Hayes, K.R.; Vollmers, C.; Pulivarthy, S.; Baggs, J.E.; Panda, S.; Hogenesch, J.B. Harmonics of circadian gene transcription in mammals. PLOS Genet. 2009, 5 , e1000442.

157. Minami, Y.; Kasukawa, T.; Kakazu, Y.; Iigo, M.; Sugimoto, M.; Ikeda, S.; Yasui, A.; van der Horst, G.T.; Soga, T.; Ueda, H.R. Measurement of internal body time by blood metabolomics. Proc. Natl. Acad. Sci. USA 2009, 106, 9890-9895.

158. Eckel-Mahan, K.L.; Patel, V.R.; Mohney, R.P.; Vignola, K.S.; Baldi, P.; Sassone-Corsi, P. Coordination of the transcriptome and metabolome by the circadian clock. Proc. Natl. Acad. Sci. USA 2012, 109, 5541-5546.

159. Kasukawa, T.; Sugimoto, M.; Hida, A.; Minami, Y.; Mori, M.; Honma, S.; Honma, K.; Mishima, K.; Soga, T.; Ueda, H.R. Human blood metabolite timetable indicates internal body time. Proc. Natl. Acad. Sci. USA 2012, 109, 15036-15041.

160. Chalkiadaki, A.; Guarente, L. Sirtuins mediate mammalian metabolic responses to nutrient availability. Nat. Rev. Endocrinol. 2012, 8, 287-296.

161. Rodgers, J.T.; Lerin, C.; Haas, W.; Gygi, S.P.; Spiegelman, B.M.; Puigserver, P. Nutrient control of glucose homeostasis through a complex of PGC-1alpha and SIRT1. Nature 2005, 434, 113 118.

162. Belden, W.J.; Dunlap, J.C. SIRT1 is a circadian deacetylase for core clock components. Cell 2008, 134, 212-214.

163. Nakahata, Y.; Kaluzova, M.; Grimaldi, B.; Sahar, S.; Hirayama, J.; Chen, D.; Guarente, L.P.; Sassone-Corsi, P. The NAD+-dependent deacetylase SIRT1 modulates CLOCK-mediated chromatin remodeling and circadian control. Cell 2008, 134, 329-340.

164. Nakahata, Y.; Sahar, S.; Astarita, G.; Kaluzova, M.; Sassone-Corsi, P. Circadian control of the NAD+ salvage pathway by CLOCK-SIRT1. Science 2009, 324, 654-657.

165. Asher, G.; Gatfield, D.; Stratmann, M.; Reinke, H.; Dibner, C.; Kreppel, F.; Mostoslavsky, R.; Alt, F.W.; Schibler, U. SIRT1 regulates circadian clock gene expression through PER2 deacetylation. Cell 2008, 134, 317-328.

166. Lamia, K.A.; Sachdeva, U.M.; DiTacchio, L.; Williams, E.C.; Alvarez, J.G.; Egan, D.F.; Vasquez, D.S.; Juguilon, H.; Panda, S.; Shaw, R.J.; et al. AMPK regulates the circadian clock by cryptochrome phosphorylation and degradation. Science 2009, 326, 437-440.

167. Liu, C.; Li, S.; Liu, T.; Borjigin, J.; Lin, J.D. Transcriptional coactivator PGC-1alpha integrates the mammalian clock and energy metabolism. Nature 2007, 447, 477-481.

168. O’Neill, J.S.; Maywood, E.S.; Chesham, J.E.; Takahashi, J.S.; Hastings, M.H. cAMP-dependent signaling as a core component of the mammalian circadian pacemaker. Science 2008, 320, 949-953.

169. Asher, G.; Reinke, H.; Altmeyer, M.; Gutierrez-Arcelus, M.; Hottiger, M.O.; Schibler, U. Poly(ADP-ribose) polymerase 1 participates in the phase entrainment of circadian clocks to feeding. Cell 2010, 142, 943-953.

170. Rudic, R.D.; McNamara, P.; Curtis, A.M.; Boston, R.C.; Panda, S.; Hogenesch, J.B.; Fitzgerald, G.A. BMAL1 and CLOCK, two essential components of the circadian clock, are involved in glucose homeostasis. PLOS Biol. 2004, 2, e377. 
171. Zhang, E.E.; Liu, Y.; Dentin, R.; Pongsawakul, P.Y.; Liu, A.C.; Hirota, T.; Nusinow, D.A.; Sun, X.; Landais, S.; Kodama, Y.; et al. Cryptochrome mediates circadian regulation of cAMP signaling and hepatic gluconeogenesis. Nat. Med. 2010, 16, 1152-1156.

172. Yin, L.; Wu, N.; Curtin, J.C.; Qatanani, M.; Szwergold, N.R.; Reid, R.A.; Waitt, G.M.; Parks, D.J; Pearce, K.H.; Wisely, G.B.; et al. Rev-erbalpha, a heme sensor that coordinates metabolic and circadian pathways. Science 2007, 318, 1786-1789.

173. Solt, L.A.; Wang, Y.; Banerjee, S.; Hughes, T.; Kojetin, D.J.; Lundasen, T.; Shin, Y.; Liu, J.; Cameron, M.D.; Noel, R.; et al. Regulation of circadian behaviour and metabolism by synthetic REV-ERB agonists. Nature 2012, 485, 62-68.

174. LeSauter, J.; Hoque, N.; Weintraub, M.; Pfaff, D.W.; Silver, R. Stomach ghrelin-secreting cells as food-entrainable circadian clocks. Proc. Natl. Acad. Sci. USA 2009, 106, 13582-13587.

175. Spiegel, K.; Leproult, R.; van Cauter, E. Impact of sleep debt on metabolic and endocrine function. Lancet 1999, 354, 1435-1439.

176. Taheri, S.; Lin, L.; Austin, D.; Young, T.; Mignot, E. Short sleep duration is associated with reduced leptin, elevated ghrelin, and increased body mass index. PLOS Med. 2004, 1, e62.

177. Scheer, F.A.; Hilton, M.F.; Mantzoros, C.S.; Shea, S.A. Adverse metabolic and cardiovascular consequences of circadian misalignment. Proc. Natl. Acad. Sci. USA 2009, 106, 4453-4458.

178. Fonken, L.K.; Workman, J.L.; Walton, J.C.; Weil, Z.M.; Morris, J.S.; Haim, A.; Nelson, R.J. Light at night increases body mass by shifting the time of food intake. Proc. Natl. Acad. Sci. USA 2010, 107, 18664-18669.

179. Hatori, M.; Vollmers, C.; Zarrinpar, A.; DiTacchio, L.; Bushong, E.A.; Gill, S.; Leblanc, M.; Chaix, A.; Joens, M.; Fitzpatrick, J.A.; et al. Time-restricted feeding without reducing caloric intake prevents metabolic diseases in mice fed a high-fat diet. Cell Metab. 2012, 15, 848-860.

180. Qian, J.; Block, G.D.; Colwell, C.S.; Matveyenko, A.V. Consequences of exposure to light at night on the pancreatic islet circadian clock and function in rats. Diabetes 2013, 62, 3469-3478.

181. Roenneberg, T.; Allebrandt, K.V.; Merrow, M.; Vetter, C. Social jetlag and obesity. Curr. Biol. 2012, 22, 939-943.

(C) 2015 by the authors; licensee MDPI, Basel, Switzerland. This article is an open access article distributed under the terms and conditions of the Creative Commons Attribution license (http://creativecommons.org/licenses/by/4.0/). 